\title{
Application of stem cells in the repair of intervertebral disc degeneration
}

\author{
Wentao Zhang ${ }^{1 \dagger}$, Tianze Sun ${ }^{1 \dagger}$, Ying Li ${ }^{4,5}$, Ming Yang ${ }^{1}$, Yantao Zhao ${ }^{3}$, Jing Liu ${ }^{4,5}$ and Zhonghai Li I $^{1,4,5^{*}}$ (D)
}

\begin{abstract}
Intervertebral disc degeneration (IDD) is a common disease that increases with age, and its occurrence is stressful both psychologically and financially. Stem cell therapy for IDD is emerging. For this therapy, stem cells from different sources have been proven in vitro, in vivo, and in clinical trials to relieve pain and symptoms, reverse the degeneration cascade, delay the aging process, maintain the spine shape, and retain mechanical function. However, further research is needed to explain how stem cells play these roles and what effects they produce in IDD treatment. This review aims to summarize and objectively analyse the current evidence on stem cell therapy for IDD.
\end{abstract}

Keywords: Intervertebral disc, Intervertebral disc degeneration, Stem cell, Therapy, Repair, Reverse degeneration

\section{Introduction}

With the acceleration of population aging, the incidence of spinal degenerative diseases has increased significantly, and the main sign is chronic low back pain, which seriously affects patients' quality of life and increases the economic burden on their family and society. Although the aetiologies of spinal degenerative diseases are varied and complex, intervertebral disc degeneration (IDD) is recognized as one of the most important causes. Degenerative disc diseases (DDDs) arising from IDD comprise a series of painful spinal diseases that include discogenic low back pain and lumbar disc herniation [1]. At present, most patients use rest or conservative treatment for pain relief, as well as a variety of drugs such as steroids, local anaesthetics, and other blocking agents. When these methods are ineffective, surgery is often performed to relieve symptoms and improve quality of life. Surgical treatments can also solve pain problems, but have disadvantages such as inability to replace decreased nucleus

\footnotetext{
*Correspondence: lizhonghaispine@126.com

'Wentao Zhang and Tianze Sun have contributed equally to the manuscript and should be considered co-first authors.

${ }^{1}$ Department of Orthopedics, First Affiliated Hospital of Dalian Medical University, Dalian, People's Republic of China

Full list of author information is available at the end of the article
}

pulposus (NP) cells, inability to reverse the pathological state of the intervertebral disc (IVD), and potential to cause various intraoperative and postoperative complications [2-4].

In recent years, with the rapid development of stem cell technologies that have been effectively applied in haematology, circulation, orthopaedics, and other fields [5-7], stem cells have attracted the attention of researchers and clinicians. With in-depth studies on the IVD and IDD as well as its mechanism, many teams have found that combination of stem cell technology and treatment for IDD can not only maintain the normal physiological function and structure of the IVD, but even reverse the IDD cascade $[8,9]$. Organic combination of the IVD and stem cell technology has outstanding advantages for IDD treatment and recovery, but remains controversial [10-12]. The present review aims to provide an overview of the current advances in stem cell therapy for IDD and to discuss the limitations of different cell applications and the future challenges of this technology.

\section{IVD and IDD}

A normal IVD consists of the NP, annulus fibrosus (AF), and upper and lower cartilaginous endplates (CEPs) [13]. The NP is tightly enclosed by the circular AF that consists of water, NP cells, notochord cells (NCs), and original author(s) and the source, provide a link to the Creative Commons licence, and indicate if changes were made. The images or other third party material in this article are included in the article's Creative Commons licence, unless indicated otherwise in a credit line to the material. If material is not included in the article's Creative Commons licence and your intended use is not permitted by statutory regulation or exceeds the permitted use, you will need to obtain permission directly from the copyright holder. To view a copy of this licence, visit http://creativecommons.org/licenses/by/4.0/. The Creative Commons Public Domain Dedication waiver (http://creativeco mmons.org/publicdomain/zero/1.0/) applies to the data made available in this article, unless otherwise stated in a credit line to the data. 
extracellular matrix (ECM). The NP is highly hydrated and its main function is to resist pressure from the spine. The AF is a concentric layered structure with 15-25 layers mainly composed of collagen (COL) I and an outer layer composed of fibroblasts with neurovascular distribution [14]. The CEPs are horizontal hyaline cartilaginous structures that act as important structures for the IVD to carry out substance exchange and information transfer. The ECM is mainly composed of COL II, fibres, elastin, and large amounts of proteoglycans, especially aggrecan (ACAN), with negative charge [15].

When IDD occurs, the NP can break through the posterior edge of the AF and contact the epidural space under the action of external forces. The antigenicity of the NP itself coupled with the inflammatory reaction caused by structural changes can stimulate the immune system to produce pain and discomfort that affect both the body and the mind. Studies have shown that prominent IVD tissue has a variety of inflammatory cell responses with important links to the IDD process. Interleukins (ILs) can regulate the activity of matrix metalloproteinases (MMPs), inhibit the synthesis of proteoglycans in the cell matrix, participate in the IDD process, and contribute to the processes of disc herniation and degeneration by regulating the production of matrix-degrading enzymes by immune cells. Tumour necrosis factor (TNF)- $\alpha$, a strong inflammatory factor, can up-regulate expression of MMP genes, stimulate production of IL-6, IL-8, and other related cytokines, promote cell migration, affect endothelial cell permeability to block collagen and proteoglycan synthesis, and induce inflammatory reactions [16-18] (Fig. 1).

Recent studies have suggested that NP cell reduction and ECM degradation form the important basis of IDD, and that its occurrence is related to massive release of pro-inflammatory cytokines. In early IDD, the number of NP cells decreases, the activity of NP cells is inhibited, and the secretion of proteoglycans decreases. As the disease progresses, the IVD water content decreases, the NP tissue fibres harden, and the spinal biomechanics change, resulting in arthritis of surrounding tissues and formation of bone spurs. In the later stages of IDD, symptoms of nerve compression can occur, and severe cases may develop spinal cord stenosis, spondylolisthesis, and degenerative scoliosis $[19,20]$.

Because the IVD has no blood vessels, its internal and external material exchanges can only occur through concentration gradients of these materials. Therefore, it is difficult to achieve healing of IDD through self-repair, and IDD exhibits the characteristics of irreversible injury [13].

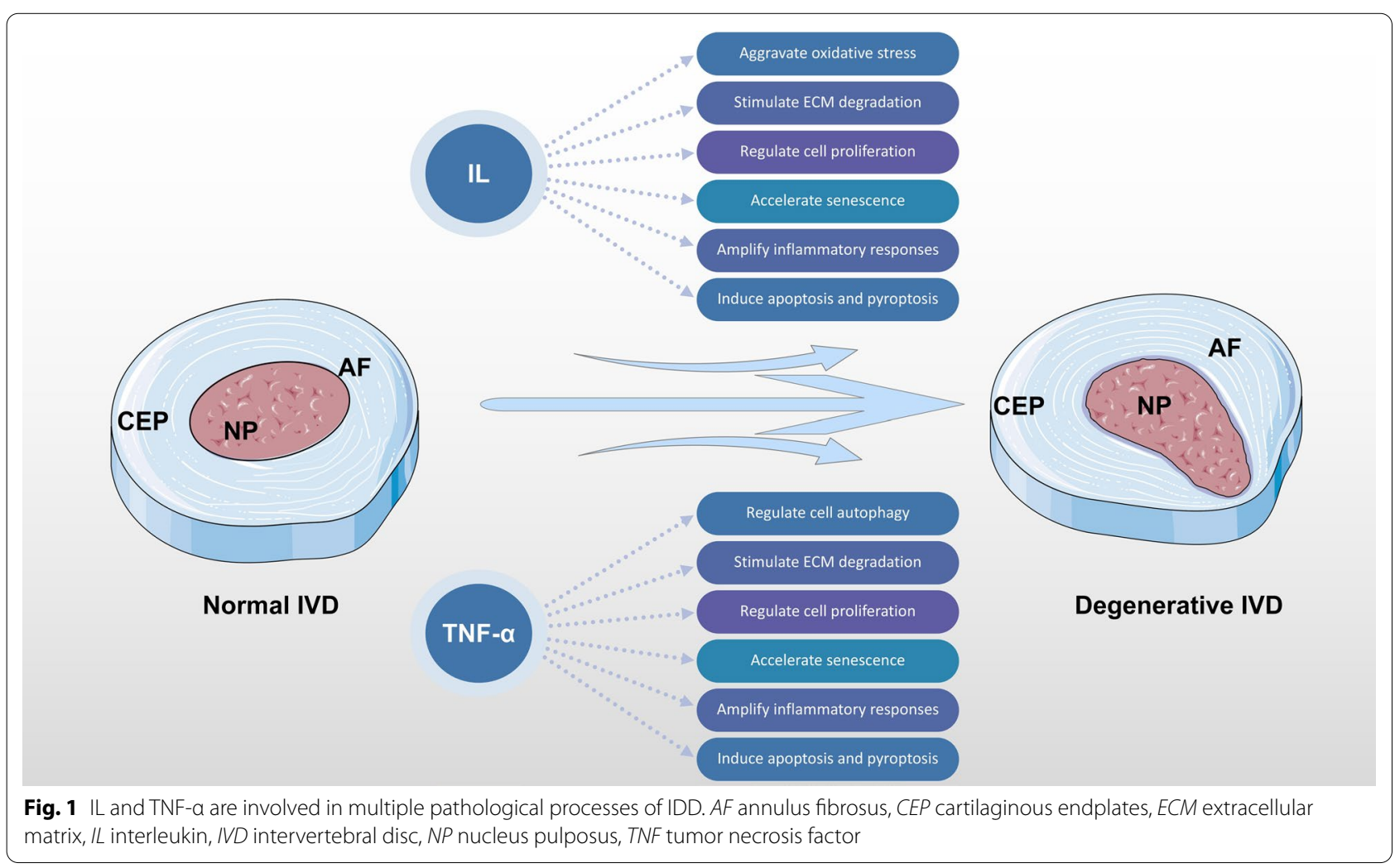




\section{Types and functions of stem cells}

Stem cells are abundant and easy to obtain, have very low immunogenicity and strong ability to induce differentiation, and can proliferate in low oxygen and low glucose environments. At present, stem cells have been applied in the treatment of many diseases in various fields [21-24].

Stem cells have been used to intervene in the IDD process to slow down IDD progression or achieve IVD repair. Stem cells currently used in IVD treatment include mesenchymal stem cells (MSCs), intervertebral disc-derived stem cells (IVDSCs), and pluripotent stem cells (PSCs). MSCs include bone marrow mesenchymal stem cells (BMSCs), adipose-derived mesenchymal stem cells (ADMSCs), and umbilical cord mesenchymal stem cells (UCMSCs), IVDSCs include nucleus pulposus stem cells (NPSCs), annulus fibrosus stem cells (AFSCs), and cartilage endplate stem cells (CESCs), and PSCs include induced pluripotent stem cells (IPSCs) and embryonic stem cells (ESCs) (Table 1).

There are three main functions for stem cells in the context of the degenerative IVD. First, stem cells can differentiate into IVD-like cells. The most promising regenerative effects for IVD implantation of stem cells are their differentiation ability into NP cells and their synthesis of new ECM. Although the survival time of cells in the harsh IVD environment or even worse IDD environment remains controversial [25-27], some reports indicated that stem cells can die soon after transplantation because of the effects of nutrition deficiency and $\mathrm{pH}$, while other reports described that MSCs and their progenitors can survive in the long term after injection as either large cell clusters and solitary cells. Second, stem cells can support the viability of resident cells at the implantation site. Many preclinical studies showed that stem cells can stimulate resident IVD cells by secreting certain growth factors, chemokines, ECM components, and anti-inflammatory substances through paracrine mechanisms. In addition to the increased ECM secretion, the expression of proteases related to cell senescence showed downward trends in co-cultures of stem cells and NP cells $[28,29]$. At the same time, stem cells can directly change the mechanical properties of NP cells and reduce the hardness of the cells and matrix to support the survival of NP cells [30-32]. Third, the IDD process can be slowed down by immune regulation. During IDD, ECM destruction is accelerated by increased pro-inflammatory cytokines that promote chemotaxis, angiopoietins, and additional cytokine release to maintain an ongoing inflammatory response mediated by ILs, TNFs, interferon (IFN)-c, prostaglandin E2 (PGE2 ), and other chemokines. These processes act together on cells, leading to further apoptosis, senescence, and autophagy. Studies have shown that when stem cells are co-cultured in an IDD-like environment in vivo or in vitro, they can produce anti-inflammatory cytokines, anti-metabolic mediators, and growth factors, thus modulating the immune response [33-35] (Fig. 2).

Table 1 Sources of stem cells for disk regeneration

\begin{tabular}{|c|c|c|c|}
\hline Cell types & Source & Advantages & Disadvantages \\
\hline \multicolumn{4}{|l|}{ MSCS } \\
\hline BMSCs & Bone marrow & $\begin{array}{l}\text { Strong self-renewal ability, multiple dif- } \\
\text { ferentiation potential, with homing ability, } \\
\text { and technology for solation and expan- } \\
\text { sion is mature }\end{array}$ & The way obtaining BMSCs is invasive \\
\hline ADMSCs & Adipose & $\begin{array}{l}\text { Abundance, ease to harvest, low immu- } \\
\text { nogenicity }\end{array}$ & $\begin{array}{l}\text { Poor ability to differentiate into chon- } \\
\text { drocytes }\end{array}$ \\
\hline UCMSCs (WJMSCs) & Umbilical cord & $\begin{array}{l}\text { Pluripotent, with no ethical barriers, strong } \\
\text { proliferation ability, extensive differentia- } \\
\text { tion ability, low immunogenicity and no } \\
\text { tumorigenicity }\end{array}$ & $\begin{array}{l}\text { Almost impossible to obtain autologous } \\
\text { cord cells, and the experimental cost of } \\
\text { WJMSCs is high }\end{array}$ \\
\hline IVDSCs & IVD & $\begin{array}{l}\text { Can be stimulated to proliferate and dif- } \\
\text { ferentiate in situ }\end{array}$ & $\begin{array}{l}\text { Low yield in number, decreased viability, } \\
\text { and expression of proteoglycan and COL } \\
\text { II in IDD, and the curative effect is not } \\
\text { obvious }\end{array}$ \\
\hline \multicolumn{4}{|l|}{ PSCS } \\
\hline IPSCs & $\begin{array}{l}\text { Artificially derived from somatic cells by } \\
\text { reprogramming with transcription factors }\end{array}$ & $\begin{array}{l}\text { High capacities of self-renewal, prolifera- } \\
\text { tion, and differentiation }\end{array}$ & $\begin{array}{l}\text { Safety problems, especially potential } \\
\text { tumorigenicity }\end{array}$ \\
\hline ESCs & Early-stage embryo & $\begin{array}{l}\text { High capacities of self-renewal, prolifera- } \\
\text { tion, and differentiation }\end{array}$ & Ethical barriers \\
\hline
\end{tabular}

ADMSCs adipose mesenchymal stem cells, BMSCs bone marrow mesenchymal stem cells, COL II collagen type II, ESCs embryonic stem cells, IDD intervertebral disc degeneration, IPSCs induced pluripotent stem cells, IVD intervertebral disc, IVDSCs intervertebral-derived stem cells, MSCs mesenchymal stem cells, PSCs pluripotent stem cells, UCMSCs umbilical cord mesenchymal stem cells, WJMSCs Wharton's Jelly mesenchymal stem cells 


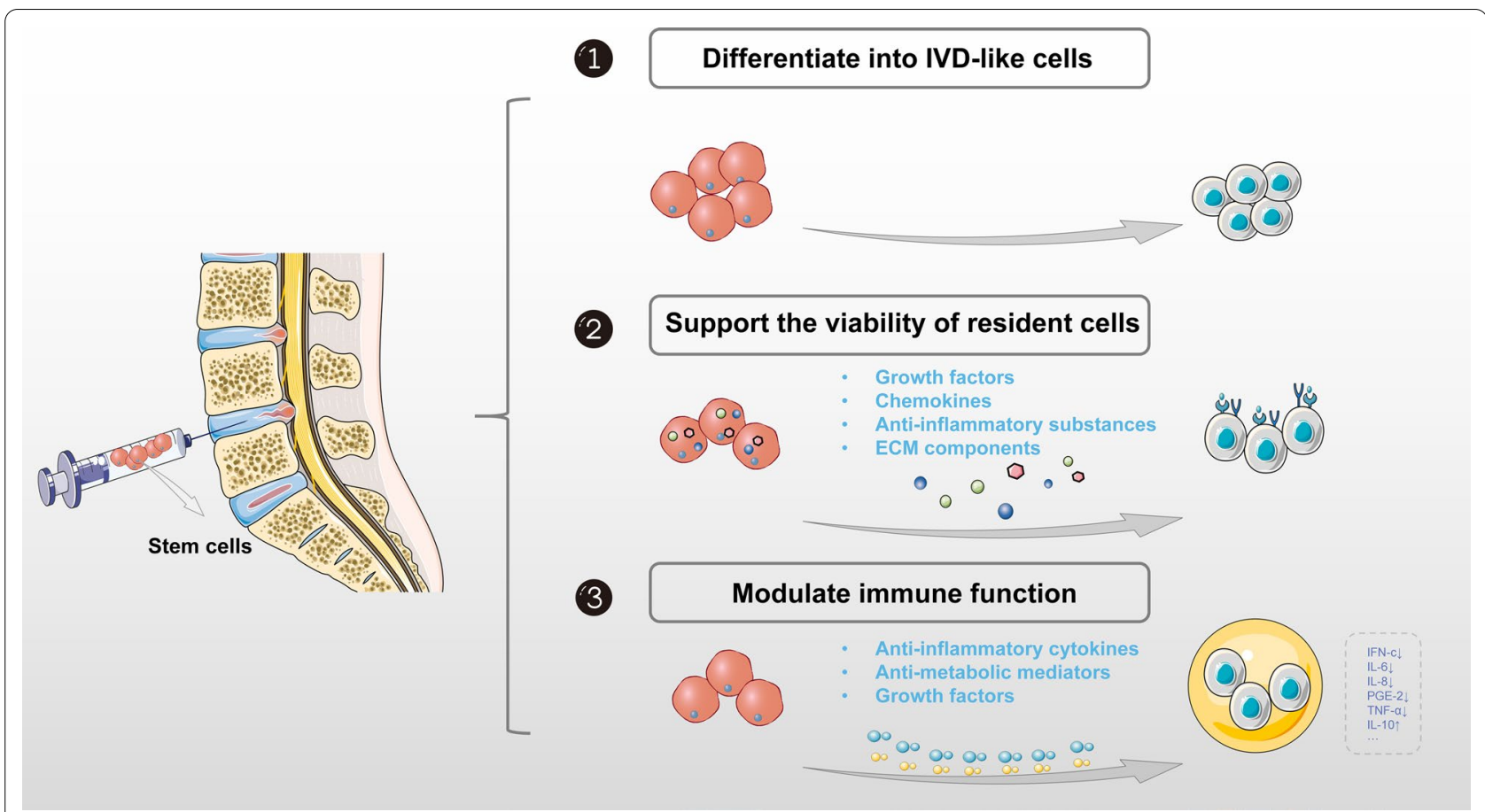

Fig. 2 The main functions for stem cells in the context of degenerative IVD. ECM extracellular matrix, IFN interferon, IL interleukin, IVD intervertebral disc; PGE prostaglandin E, TNF tumor necrosis factor

\section{In vitro, in vivo, and clinical applications of stem cells in IDD BMSCs}

BMSCs are non-hematopoietic stem cells in the bone marrow that possess self-renewal ability, multiple differentiation potential, and certain homing ability, and can enhance the survival and regeneration of IVD cells and prevent further deterioration of IDD [36]. BMSCs can repair degenerated IVD tissues by promoting cell proliferation and enhancing production of COL I, proteoglycans, and other ECM components. Fasudil in the TNF family can induce homing of BMSCs [37]. Studies showed that bone morphogenetic protein (BMP)-3, BMP-7, and transforming growth factor (TGF)- $\beta 1$ can induce BMSCs to differentiate into the NP cell phenotype, and confirmed that appropriate gene transfection can promote the transformation of BMSCs to NP cells [38-40]. In 2003, Sakai et al. [41] first found that autologous BMSCs embedded in atelocollagen gel and transplanted into a rabbit IDD model could delay degeneration of the IVD, and thus studies on BMSCs in IDD were initiated.

Direct and indirect findings from in vitro experiments have shown that BMSCs are beneficial for treatment of IDD. Cao et al. [42] co-cultured BMSCs with NP cells, and found that this combination significantly delayed degeneration of the NP cell matrix by up-regulating TGF- $\beta$ expression and inhibiting expression of the NF-KB signalling pathway. Fasudil induced actin stress fibre formation by activating the mitogen-activated protein kinase (MAPK) signalling pathway in vitro to promote the migration of rat BMSCs and effectively improve the homing ability of BMSCs [37]. When BMSCs and ADMSCs were separately co-cultured with AF cells for 21 days, the expression of the COL I, COL II, and proteoglycan genes in BMSCs and ADMSCs was increased, and both cell types were able to differentiate into AF cells. Among them, the AF marker COL I was most strongly expressed in the BMSC group, suggesting that BMSCs had stronger ability to differentiate into AF cells and could represent a better cell source for AF repair [43]. When BMSCs were co-cultured with NP cells, the expression of senescence-related genes in NP cells was decreased, i.e. the expression of $\beta$-galactosidase was decreased, the synthesis of MMP9 was decreased, and the amount of COL II was increased. At the same time, the expression of zinc metallopeptidase STE24 in NP cells recovered from an inhibition level to the normal level after co-culture, confirming that inhibition of the NF-KB signalling pathway can slow or prevent the aging of NP cells $[44,45]$. NCs are key cells for IVD regeneration, and can produce proteoglycans that promote IVD repair. NCs have a stronger ability to tolerate the environment than NP cells, and are thus speculated to be the best seed source for IVD repair. However, NCs disappear when the human body 
reaches about 10 years of age, which limits their extraction and isolation from the human IVD. Some researchers induced BMSCs from pigs using the NP external matrix and successfully differentiated NCs, providing a new cell source direction for IDD repair by cell transplantation. Indirect evidence confirmed the transformation of BMSCs into NP cells. Regarding co-cultures of BMSCs with NP cells, indirect co-cultures showed that BMSCs produced the NP cell phenotype, while direct cocultures revealed that BMSCs not only transformed into NP cells, but also formed a similar tunnelling nanotube structure between cell membranes that promoted the phenotypic differentiation of BMSCs. These experiments revealed the relationship between stem cells and NP cells at the level of the molecular mechanism for cell communication [46]. Exosomes (Exos), one of the key messengers for cellular communication, play important roles in material exchange and information transfer between cells. Lu et al. [47] found that exosomes from NP cells (NP-exos) could successfully induce BMSCs to differentiate into NP cells, while exosomes from BMSCs (BMSCexos) could promote the expression of NP cell-related genes and increase ECM production, thereby achieving the effect of IVD self-repair. BMSC-exos can suppress the NP cell apoptosis induced by TNF- $\alpha$, and this phenomenon may be related to the transfer of exosome microRNAs targeting activation of the PI3K/AKT pathway [48]. BMSC-exos also inhibit the activation of certain inflammatory mediators and the NLRP3 inflammasome to exert anti-inflammatory effects in NP cells, thereby preventing the occurrence of degenerative changes [49]. Exos have become a new therapeutic approach to reverse IDD due to their low immunogenicity, stable properties, easy acquisition and preservation, and simple transformation. However, due to their disadvantages of low productivity and high heterogeneity, the current applications of exos are limited (Table 2).

Regarding in vivo experiments, Sakai et al. [50] transplanted autologous BMSCs into a rabbit IDD model, and found that the number of IVD cells increased, the cell survival rate increased, and the proteoglycan content also increased. After injection of human BMSCs into the NP of a bovine IDD model, BMSC apoptosis and migration were regularly detected, and the results showed that the IDD environment did not affect the activity of BMSCs and allowed the cells to migrate to the injured site. At the same time, it was speculated that the stem cells may down-regulate the expression of IL-6, IL- 8 , and TNF- $\alpha$ through paracrine mechanisms, thus delaying the progression of IDD [35]. An acellular high-density collagen gel loaded with BMSCs was inoculated into the IVD of sheep with AF injury. At 6 weeks after transplantation, the disc height index (DHI), Pfirrmann grade, NP area, and other data were better than those in the control group. Meanwhile, the repair and reconstruction of AF and NP tissues were significantly improved histologically [51]. In terms of efficacy, BMSCs combined with salvianolic acid B had a better effect for IVD repair than BMSCs alone [52]. An IDD model was formed under hydrogen peroxide-induced stress, and then BMSCs and erythropoietin (EPO) were mixed into the IVD of the model. After a period of time, both imaging and histological findings showed that the IVD height and the composition of NP cells were improved. It was also confirmed that EPO could inhibit MSC migration under oxidative stress and stimulate MSC regeneration through local

Table 2 The application of BMSCs in vitro

\begin{tabular}{|c|c|c|c|}
\hline Year & Team & Source of stem cells & Results \\
\hline 2014 & Lehmann et al. [46] & Human BMSCs + Human NP cells & $\begin{array}{l}\text { BMSCs differentiate into NP cells in indirect co-culture group, and form tunneling } \\
\text { nanotubes structure which can promote the differentiation of BMSCs in direct co- } \\
\text { culture group }\end{array}$ \\
\hline 2015 & Cao et al. [42] & Rabbit BMSCs + rabbit NP cells & NP cells matrix degenerate delay, TGF- $\beta$ expression $\uparrow$, inhibit NF-KB signaling pathway \\
\hline 2017 & Zhou et al. [43] & Rabbit BMSCs/ADMSCs + AF cells & $\begin{array}{l}\text { COL I, COL II and proteoglycan content } \uparrow \text { in both two group, MSCs differentiate into AF } \\
\text { cells in both two group, BMSCs perform better than ADMSCs }\end{array}$ \\
\hline 2017 & Lu et al. [47] & Human NP-exos + human BMSCs & BMSCs differentiate into NP cells, ECM $\uparrow$ \\
\hline 2018 & Zhan et al. [37] & Rat BMSCs + Fasudil & $\begin{array}{l}\text { Activate MAPK signaling pathway, promote BMSCs migration, improve the homing } \\
\text { ability of BMSCs }\end{array}$ \\
\hline 2018 & Cheng et al. [48] & Human BMSCs-exos + NP cells & Activate PI3K/AKT signaling pathway to inhibit NP cells apoptosis induced by TNF-a \\
\hline 2019 & Li et al. [44] & Rat BMSCs + rat NP cells & $\begin{array}{l}\text { COL II content } \uparrow, \text { MMP9 synthesis } \downarrow \text {, } \beta \text {-galactosidase expression } \downarrow \text {, inhibiting NF-KB } \\
\text { signaling pathway can slow the aging of NP cells }\end{array}$ \\
\hline 2019 & Li et al. [45] & Pig BMSCs + pig NP cells ECM & BMSCs differentiate into NP cells \\
\hline 2019 & Xia et al. [49] & Human BMSCs-exos + NP cells & Inhibit the activation of inflammatory mediators and NLRP3 inflammasome \\
\hline
\end{tabular}

ADMSCs adipose mesenchymal stem cells, $A F$ annulus fibrosus, BMSCs bone marrow mesenchymal stem cells, BMSCs-exos bone marrow mesenchymal stem cells exsomes, COL I collagen type I, COL I/ collagen type II, ECM extracellular matrix, MAPK mitogen activated protein kinase, MMPs matrix metalloproteinases, MSCs mesenchymal stem cells, NP nucleus pulposus, NP-exos nucleus pulposus exsomes, TGF transforming growth factor, TNF tumor necrosis factor 
accumulation [53]. Yi et al. [54] obtained transgenic rabbit BMSCs (TBTs) by transfection with a recombinant adenovirus vector carrying human metalloproteinase tissue inhibitor (hTIMP)-1, and implanted them into the rabbit IDD model. Compared with the normal BMSC transplantation group, the degree of IDD in the TBT group was significantly improved, the content of ECM was significantly increased, and the hTIMP-1 mRNA and protein expression levels were higher than those in the normal group. In terms of immune rejection, Shi et al. [55] compared the host immune response to human neonatal and rabbit dermal fibroblasts in a rabbit IDD model, and found that the immune response to human cells implanted into the rabbit IVD was smaller than that to rabbit cells, further indicating that the IVD can tolerate transplantation of allogeneic or xenogeneic cells. Experiments in vivo also indirectly reflected the fact that cell transplantation in combination with loaded genes or drugs may have better therapeutic effects (Table 3).

In a clinical study, Orozco et al. [56] injected autologous BMSCs into the NP of ten patients with chronic low back pain caused by lumbar IDD. After 12 months, the patients' low back pain was significantly relieved and the IVD water content was significantly increased on imaging, but the height of the IVD had not changed significantly. Mochida et al. [57] co-cultured NP cells with autologous BMSCs for 1 week, and then implanted the activated NP cells into the IVD adjacent to an interbody fusion segment. Within 3 years of follow-up, they found that the JOA scores had increased, no symptoms of low back pain recurred in all 9 patients, and no adverse reactions after transplantation were observed on imaging. Elabd et al. [58] injected autologous BMSCs cultured under hypoxia into the IVD of five patients with chronic low back pain, and found that the volume of protrusions decreased in four patients during short-term followup. In the long-term follow-up, the IVD height in all five patients was maintained or slightly decreased, and the overall condition was improved. Centeno et al. [59] injected autologous BMSCs into the IVD of 33 patients with low back pain and IVD prolapse, and found that this method had significant benefits in alleviating pain, enhancing spinal function, and reducing the IVD prolapse size. Pettine et al. [60] injected autologous BMSCs into the IVD of 26 patients with indications for spinal fusion or IVD replacement. They observed significant improvement in the degree of IDD after 1 year, and only six patients required surgical treatment to improve symptoms within 3 years. Henriksson et al. [61] injected autologous BMSCs into the IVD of four IDD patients. After 8 months, BMSCs were observed to survive in different parts of the IVD and differentiate into chondrocytes, and the original cells were continuously stimulated to produce ECM. Noriega et al. [62] used allogeneic BMSCs to treat 12 patients with chronic low back pain and lumbar IDD who had failed conservative treatment. After 12 months, the VAS, ODI, and Pfirrmann levels in all patients were significantly improved compared with the control group (Table 8).

At present, both autologous BMSCs and allogeneic BMSCs have shown excellent therapeutic effects. Nevertheless, although autologous BMSCs have higher homogeneity, lower treatment cost, wider application, and better therapeutic effect, autologous BMSCs remain the preferred cells in stem cell therapy. However, the method for obtaining BMSCs is invasive, the sample size for clinical treatment is relatively limited, and the long-term efficacy is unknown, warranting further research.

Table 3 The application of BMSCs in vivo

\begin{tabular}{|c|c|c|c|c|c|}
\hline Year & Team & Source of stem cells & Model & Observation time & Results \\
\hline 2006 & Sakai et al. [50] & Rabbit BMSCs & Rabbit IDD model & 24 weeks & $\begin{array}{l}\text { IVD cells } \uparrow \text {, cell survival rate } \uparrow \text {, proteoglycan } \\
\text { content } \uparrow\end{array}$ \\
\hline 2014 & Yi et al. [54] & Transgenic rabbit BMSCs & Rabbit IDD model & 12 weeks & $\begin{array}{l}\text { IVD degeneration } \downarrow, \text { ECM } \uparrow, \mathrm{hTIMP}-1 \mathrm{mRNA} \text { and } \\
\text { protein expression levels } \uparrow\end{array}$ \\
\hline 2018 & Teixeira et al. [35] & Human BMSCs & Bovine IDD model & 16 days & $\begin{array}{l}\text { BMSCs migrate directionally, the expression of } \\
\text { IL-6,IL-8,TNF- } a \downarrow \text { by paracrine stimulation }\end{array}$ \\
\hline 2019 & Hussain et al. [51] & $\begin{array}{l}\text { Allogeneic sheep BMSCs + acel- } \\
\text { lular high-density collagen gel }\end{array}$ & Sheep IDD model & 6 weeks & $\begin{array}{l}\text { DHI, Pfirrmann grade, NP area all perform well, } \\
\text { AF and NP tissue improve in histology }\end{array}$ \\
\hline 2019 & Shi et al. [55] & $\begin{array}{l}\text { Neonatal dermal fibro- } \\
\text { blasts + rabbit dermal fibroblasts }\end{array}$ & Rabbit IDD model & 8 weeks & $\begin{array}{l}\text { IVD can tolerate transplantation of allogeneic or } \\
\text { xenogeneic cells }\end{array}$ \\
\hline 2020 & Yan et al. [52] & Rabbit BMSCs + salvianolic acid B & Rabbit IDD model & 8 weeks & $\begin{array}{l}\text { Salvianolic acid B can improve the repair effect } \\
\text { of BMSCs }\end{array}$ \\
\hline 2020 & Lykov et al. [53] & Rat BMSCs + EPO & Rat IDD model & 21 days & $\begin{array}{l}\text { IVD height } \uparrow, \text { NP content change, EPO can inhibit } \\
\text { the migration of MSCs to prevent IVD repair }\end{array}$ \\
\hline
\end{tabular}




\section{ADMSCs}

ADMSCs, another kind of stem cells with multiple differentiation potential, are more widely derived and can be isolated from adipose tissue. Some studies showed that ADMSCs have stronger differentiation ability than BMSCs and are more suitable for treatment of DDDs [63, 64]. However, there is also evidence that ADMSCs have lower endochondral osteogenic ability than BMSCs [65].

When ADMSCs were cultured with TGF- $\beta 3$ in vitro, increased amounts of IVD cells and ECM components were observed [66]. At the same time, under induction by TGF- $\beta 1$, growth differentiation factor (GDF)-5, or GDF-6, ADMSCs had stronger ability to differentiate into NP cells than BMSCs, and the expression levels of ECM components such as sulphated glycosaminoglycans and COL II were significantly higher in the medium [67]. When ADMSCs and NP cells were co-cultured in COL II hydrogel, the number of COL II-secreting NP cells was increased and the expression of the ACAN gene was up-regulated [68]. When rat BMSCs and ADMSCs were separately cultured in a three-dimensional culture system and compared with BMSCs in three-dimensional culture, ADMSCs in three-dimensional culture exhibited higher mRNA and protein expression of NP cell marker genes such as HIF1- $\alpha$, glucose transporter-1, and chondrocytespecific genes such as Sox-9, ACAN, and COL II. These findings indicated that ADMSCs had better ability to differentiate into NP cells in three-dimensional culture [69]. In a study on co-culture of ADMSCs and degenerative NP cells, Han et al. [70] found that degenerative NP cells exhibited differential expression of lncRNAs and mRNAs, and subsequently explored the relationship between ADMSCs and NP cells in this co-culture system at the gene expression level. Sun et al. [71] evaluated the effect of ADMSCs on NP cells in a non-physiological mechanical stimulation environment, and found that ADMSCs prevented NP apoptosis by inhibiting caspase-9 and caspase-3, and promoted the TIMP expression by increasing the amount of ECM, thereby inhibiting the effect of MMPs. In addition, the expression of proteoglycans and proinflammatory factors in this system had a positive influence on NP stability. Han et al. [72] co-cultured ADMSCs with degenerative NP cells, and explored the involved signalling pathways and regulatory networks through the IncRNA and mRNA expression profiles in the system. The results showed that ADMSCs in the co-culture system differentially expressed 360 lncRNAs and 1757 mRNAs, had 589 up-regulated genes and 661 down-regulated genes, and showed changes in 299 signalling pathways (Table 4).

When ADMSCs were injected into a mouse IDD model in vivo, significant positive imaging findings revealed that signals in the IVD were significantly enhanced, with new expression of biglycan and significantly enhanced level of ACAN at 12 weeks after ADMSC implantation [64]. In a study on canine IDD repair, an IDD model was treated with hyaluronic acid (HA) loaded with autologous ADMSCs, and the production of proteoglycans and COL II in the experimental group was significantly increased, indicating that ADMSCs had a stronger stimulating effect on IVD regeneration compared with the control group without ADMSCs [73]. In other experiments, ADMSCs were loaded into acellular NP scaffolds that simulated natural NP components, and the scaffolds were implanted into a rabbit IDD model. The results showed that the combined system had similar mechanical properties and biocompatibility to fresh NP and that the ADMSCs in the scaffolds differentiated into NP cells, while ECM synthesis was also increased [74]. Ishiguro et al. [75] prepared a stent-free tissue engineering structure (TEC) using ADMSCs and applied it to a rat IVD model after NP resection. At 6 weeks after implantation, the TEC showed similar biomechanical characteristics to a sham operation group, while at 6 months, the ADMSC-TEC had not

Table 4 The application of ADMSCs in vitro

\begin{tabular}{|c|c|c|c|}
\hline Year & Team & Source of stem cells & Results \\
\hline 2008 & Lu et al. [68] & Human ADMSCs + NP cells & COL II content $\uparrow, A C A N$ gene expression $\uparrow$ \\
\hline 2013 & Jin et al. [66] & Rat ADMSCs + TGF- $\beta 3$ & IVD cells $\uparrow, E C M \uparrow$ \\
\hline 2014 & Clarke et al. [67] & Human ADMSCs + TGF- $\beta 1$, GDF-5, GDF-6 & $\begin{array}{l}\text { COL II, glycosaminoglycan content } \uparrow, E C M \uparrow, \text { ability of ADMSCs differentiating into } \\
\text { NP cells } \uparrow\end{array}$ \\
\hline 2015 & Sun et al. [71] & Human ADMSCs & ECM $\uparrow$, TIMP expression $\uparrow$, inhibit caspase-3, caspase-9 \\
\hline 2018 & Han et al. [70] & Human ADMSCs + degenerative NP cells & Inc RNA and mRNA express differentially \\
\hline 2021 & Dai et al. [69] & Rat BMSCs/ADMSCs & $\begin{array}{l}\text { ADMSCs perform better in NP cells markers genes and chondrocyte-specific genes } \\
\text { expression than BMSCs }\end{array}$ \\
\hline 2021 & Han et al. [72] & Human ADMSCs + degenerative NP cells & $\begin{array}{l}\text { Express } 360 \text { IncRNA and } 1757 \text { mRNA differentially, } 589 \text { genes expression } \uparrow, 661 \\
\text { expression } \downarrow, 299 \text { signaling pathway change }\end{array}$ \\
\hline
\end{tabular}


only maintained the height of the IVD, but also retained the AF and CEPs. A major advantage of the TEC-IVD is that it does not degenerate with aging and can thus provide an optimal direction for future treatment of IVD repair. Smoothened Agonist (SAG) can effectively activate the sonic hedgehog (Shh) signalling pathway to promote the differentiation of ADMSCs into NP cells. Hua et al. [76] pre-treated ADMSCs with SAG, as a specific signal agonist of the Shh signalling pathway, and found that the combination of SAG and TGF- $\beta 3$ significantly increased the gene and protein expression of NP-specific markers at the molecular level as well as the macromolecular level, and significantly changed the IVD height, water content, ECM content, and structure (Table 5).

In a clinical study, Kumar et al. [77] implanted a mixture of HA and ADMSCs into the IVD of ten IDD patients. At the 1-year follow-up, no adverse reactions were found and more than one-half of the patients showed significant improvement in the VAS and ODI, with only three patients showing an increased IVD water content on imaging (Table 8).

Like BMSCs, ADMSCs also have the ability to differentiate into NP cells, produce different growth factors, and play a role in IVD repair at different levels. ADMSCs have a wide range of sources and are easy to obtain, providing unique advantages over other stem cells and having bright prospects for application. However, the number of clinical trials is not currently sufficient to support the long-term effectiveness and safety of the technology.

\section{UCMSCs}

UCMSCs mainly exist in Wharton's Jelly of the umbilical cord, and are also known as Wharton's Jelly mesenchymal stem cells (WJMSCs). Although these stem cells are not limited by ethical barriers, they cannot be obtained autologously for IDD patients. Compared with most other MSCs, WJMSCs are a relatively young type of MSCs with strong proliferation ability, extensive differentiation ability, low immunogenicity, and no tumorigenicity $[78-80]$.

The gene expression pattern in WJMSCs in vitro is similar to that in ADMSCs, and can be regulated by inflammatory stimulation [81]. Beeravolu et al. [82] induced differentiation of WJMSCs into chondrogenic progenitor cells (CPCs) in vitro, and found that the cell structure, ECM, and glycosaminoglycan content of CPCs were significantly improved compared with original WJMSCs. Other experiments showed that WJMSCs significantly increased the expression of proteoglycans and COL II in the NP, thus promoting ECM formation. WJMSCs were able to regulate mitosis and apoptosis by up-regulating expression of Bcl-2 and down-regulating expression of Bax, thereby protecting NP cells against high glucose damage [83]. Meanwhile, WJMSCs mitigated ECM degradation in a high glucose environment through the P38 MAPK signalling pathway, producing conditions conducive to IVD repair. Compared with IDD patients showing mild degeneration, caspase-3, Bax, Wnt3a, Wnt5a, Wnt10a, GSK-3 $\beta$, cyclin-D1, and $\beta$-catenin expression was significantly increased with IDD progression, while Bcl-2 expression was significantly decreased in patients with severe IDD. Zhao et al. [84] isolated NP cells from patients with mild or severe IDD, induced apoptosis by compression, and conducted co-cultures with WJMSCs. They found that the apoptotic ratio of NP cells increased, but was significantly reversed on co-culture with WJMSCs. Meanwhile, WJMSCs also blocked the Wnt/ $\beta$ catenin pathway through DKK-1 to inhibit the expression of Wnt-related genes, thus guaranteeing the anti-apoptotic effect of WJMSCs (Table 6).

In an in vivo study, McKee et al. [91] loaded WJMSCs and rabbit degenerative NP cells into a specific scaffold

Table 5 The application of ADMSCs in vivo

\begin{tabular}{|c|c|c|c|c|c|}
\hline Year & Team & Source of stem cells & Model & Observation time & Results \\
\hline 2009 & Ganey et al. [73] & Canine ADMSCs + HA & Canine IDD model & 12 months & COL II, proteoglycan content $\uparrow$, cell density $\uparrow$ \\
\hline 2014 & Marfia et al. [64] & Human ADMSCs & Rat IDD model & 12 weeks & $\begin{array}{l}\text { Biglycan content } \uparrow, A C A N \text { gene expression } \uparrow, \\
\text { imaging signals in IVD } \uparrow\end{array}$ \\
\hline 2018 & Zhou et al. [74] & $\begin{array}{l}\text { Human ADMSCs+ pig } \\
\text { acellular NP scaffold }\end{array}$ & Rabbit IDD model & 16 weeks & $\begin{array}{l}\text { ECM } \uparrow \text {, the mechanical properties and bio- } \\
\text { compatibility of the combination system are } \\
\text { brilliant, ADMSCs differentiate into NP cells }\end{array}$ \\
\hline 2019 & Ishiguro et al. [75] & Transgenic rat ADMSCs & Rat IDD model without NP & 6 months & $\begin{array}{l}\text { Biomechanical properties are maintained in } \\
6 \text { weeks, IVD height maintain, AF and CEPs } \\
\text { retain in } 6 \text { months }\end{array}$ \\
\hline 2019 & Hua et al. [76] & Pretreated human ADMSCs & Rat tail IDD model & 16 weeks & $\begin{array}{l}\text { NP-specific markers genes expression and } \\
\text { ECM } \uparrow, \text { IVD height, water content and ECM } \\
\text { content all change }\end{array}$ \\
\hline
\end{tabular}


Table 6 The application of WJMSCs, IVDSCs and PSCs in vitro

\begin{tabular}{|c|c|c|c|}
\hline Year & Team & Source of stem cells & Results \\
\hline 2016 & Wang et al. [81] & Human WJMSCs & $\begin{array}{l}\text { WJMSCs genes expression pattern is similar to ADMSCs, inflammatory } \\
\text { stimulation can regulate genes expression }\end{array}$ \\
\hline 2018 & Beeravolu et al. [82] & Induce human WJMSCs differentiating into CPCS & Cell structure change, glycosaminoglycan content and ECM $\uparrow$ \\
\hline 2019 & Qi et al. [83] & Human WJMSCs & $\begin{array}{l}\text { Activate MAPK signaling pathway, promote B-cell lymphoma-2 expres- } \\
\text { sion and inhibit Bax expression, ECM } \uparrow \text { and ECM degradation } \downarrow \text {, COL II } \\
\text { and proteoglycan content } \uparrow \text {, regulate mitosis and apoptosis }\end{array}$ \\
\hline 2020 & Zhao et al. [84] & Human WJMSCs + human NP cells & $\begin{array}{l}\text { Reverse the apoptotic ratio of NP cells, block Wnt/ } \beta \text {-catenin pathway to } \\
\text { inhibit Wnt-related genes expression }\end{array}$ \\
\hline 2013 & Barreto et al. [85] & Rabbit NPSCs & NPSCs migrate along the fibers and cells in IVD \\
\hline 2016 & Wang et al. [86] & BMSCs/NPSCs/AFSCs/CESCs & $\begin{array}{l}\text { CESCs are stronger in osteogenesis and chondrogenesis than the other } \\
\text { three }\end{array}$ \\
\hline 2017 & Huang et al. [87] & NPSCs & $\begin{array}{l}\text { Hypoxia can promote NPSCs proliferation related to HIF-1 a signaling } \\
\text { pathway, Simvastatin can promote NPSCs transfer into NP cells }\end{array}$ \\
\hline 2018 & He et al. [88] & Human CESCs & Promote CEPs repair, promote NP cells proliferation \\
\hline 2015 & Liu et al. [89] & Human IPSCs + pig NP cell ECM & $\begin{array}{l}\text { NP cells secret regulatory factors, mediate the differentiation of IPSCs } \\
\text { into NP cells }\end{array}$ \\
\hline 2020 & Hu et al. [90] & GDF-5 transfected human IPSCs + rat NP cells & Chondrocyte markers genes expression $\uparrow$ \\
\hline
\end{tabular}

ADMSCs adipose mesenchymal stem cells, AFSCs annulus fibrosus stem cells, BMSCs bone marrow mesenchymal stem cells, CEPs cartilaginous endplates, CESCs cartilage endplate stem cells, COL II collagen type II, CPCS chondrogenic progenitor cells, ECM extracellular matrix, GDF growth differentiation factor, HIF hypoxia inducible factor, IPSCs induced pluripotent stem cells, IVD intervertebral disc, MAPK mitogen activated protein kinase, NP nucleus pulposus, NPSCs nucleus pulposus stem cells, WJMSCs Wharton's Jelly mesenchymal stem cells

and conducted experiments in a rabbit IDD model. They found that this combination not only promoted the transformation of WJMSCs into NP cells, but also prevented cell leakage during and after implantation, avoided complications, and achieved the effect of IVD repair by transplantation of stem cells. After WJMSCs were induced to differentiate into CPCs and implanted into a rabbit IDD model, NP-specific markers were more significantly expressed in the CPC group compared with the WJMSC group [82] (Table 7).

In a clinical study, two patients with chronic discogenic low back pain were treated with IVD injection of WJMSCs. During follow-up for 2 years, the VAS and ODI in both patients were significantly improved, and

Table 7 The application of WJMSCs, IVDSCs and PSCs in vivo

\begin{tabular}{|c|c|c|c|c|c|}
\hline Year & Team & Source of stem cells & Model & Observation time & Results \\
\hline 2018 & Beeravolu et al. [82] & WJMSCs differentiate into CPCs & Rabbit IDD model & 8 weeks & $\begin{array}{l}\text { NP-specific markers genes express } \\
\text { more significantly in CPCs group }\end{array}$ \\
\hline 2020 & McKee et al. [91] & $\begin{array}{l}\text { Human WJMSCs + degenerative } \\
\text { rabbit NP cells + scaffold }\end{array}$ & Rabbit IDD model & 8 weeks & $\begin{array}{l}\text { Promote WJMSCs differentiating } \\
\text { into NP cells, avoid cell leakage and } \\
\text { complications }\end{array}$ \\
\hline 2016 & Chen et al. [92] & Human NPSCs/NP cells & Rabbit IDD model & 8 weeks & $\begin{array}{l}\text { NPSCs have better IVD repair effect } \\
\text { than NP cells }\end{array}$ \\
\hline 2021 & Marimuthu et al. [93] & Rat NPSCs & Allogeneic rat IDD model & 21 days & $\begin{array}{l}\text { NPSCs regenerative abil- } \\
\text { ity is stronger, MSCs anabolic } \\
\text { activity } \uparrow \text { and catabolic activity } \\
\downarrow \text {, allotransplantation cause pro- } \\
\text { inflammatory effect stronger }\end{array}$ \\
\hline 2009 & Sheikh et al. [94] & Rat ESCs & Rabbit IDD model & 8 weeks & Generate NCs \\
\hline 2020 & Hu et al. [90] & $\begin{array}{l}\text { Transfected human IPSCs + GDF-5 } \\
\text { hydrogel }\end{array}$ & Rat IDD model & 3 months & $\begin{array}{l}\text { IDD symptoms improve both in } \\
\text { imaging and histology }\end{array}$ \\
\hline 2021 & Sun et al. [95] & Transfect human IPSCs to IMSCs & Rat IDD model & 8 weeks & $\begin{array}{l}\text { NP cells senescence delay, and } \\
\text { restore the age-related function, } \\
\text { activate SIRT6 pathway, downregu- } \\
\text { late PDE4D level }\end{array}$ \\
\hline
\end{tabular}

CPCs chondrogenic progenitor cells, ESCs embryonic stem cells, GDF growth differentiation factor, IDD intervertebral disc degeneration, IMSCs induced mesenchymal stem cells, IVD intervertebral disc, IPSCs induced pluripotent stem cells, MSCs mesenchymal stem cells, NCs notochord cells, NP nucleus pulposus, NPSCs nucleus pulposus stem cells, WJMSCs Wharton's Jelly mesenchymal stem cells 
Table 8 The application of stem cells in clinic

\begin{tabular}{|c|c|c|c|c|c|}
\hline Year & Team & Types of cells & $\begin{array}{l}\text { Number } \\
\text { of cases }\end{array}$ & Observation time & Results \\
\hline 2011 & Orozco et al. [56] & Autologous BMSCs & 10 & 12 months & IVD water content $\uparrow$, IVD height do not change \\
\hline 2015 & Mochida et al. [57] & Autologous BMSCs + NP cells & 9 & 3 years & $\begin{array}{l}\text { JOA } \uparrow \text { in } 9 \text { patients, no symptoms of low back pain, no } \\
\text { adverse reactions }\end{array}$ \\
\hline 2016 & Elabd et al. [58] & Autologous BMSCs under hypoxia & 5 & Long-term & $\begin{array}{l}\text { Protrusions volume } \downarrow \text { in } 4 \text { patients, IVD height keep or } \\
\text { slightly } \downarrow\end{array}$ \\
\hline 2017 & Centeno et al. [59] & Autologous BMSCs & 33 & 6 years & Pain $\downarrow$, spinal function $\uparrow$, disc prolapse $\downarrow$ \\
\hline 2017 & Pettine et al. [60] & Autologous BMSCs & 26 & 3 years & $\begin{array}{l}\text { IVD function } \uparrow \text { in all patients in } 1 \text { year, only } 6 \text { patients } \\
\text { need surgical treatment in } 3 \text { years }\end{array}$ \\
\hline 2017 & Noriega et al. [62] & Allogeneic BMSCs & 12 & 12 months & VAS, ODI and Pfirrmann levels all perform well \\
\hline 2019 & Henriksson et al. [61] & Autologous BMSCs & 4 & 8 months & BMSCs differentiate into chondrocytes, ECM $\uparrow$ \\
\hline 2017 & Kumar et al. [77] & Human ADMSCs + HA & 10 & 12 months & $\begin{array}{l}\text { VAS and ODI perform better over } 5 \text { patients, IVD water } \\
\text { content } \uparrow \text { in } 3 \text { patients, no adverse reactions }\end{array}$ \\
\hline 2014 & Pang et al. [96] & Human WJMSCs & 2 & 2 years & VAS, ODI perform well \\
\hline
\end{tabular}

ADMSCs adipose mesenchymal stem cells, BMSCs bone marrow mesenchymal stem cells, $D H I$ disc height index, ECM extracellular matrix, $H A$ hyaluronic acid, IVD intervertebral disc, JOA Japanese Orthopaedic Association scores, NP nucleus pulposus, ODI Oswestry Disability Index, VAS visual analogue scale, WJMSCs Wharton's Jelly mesenchymal stem cells

their pain symptoms were significantly alleviated [96] (Table 8).

WJMSCs are rarely used in the treatment of IDD. Nevertheless, experiments have confirmed that WJMSCs can be induced to differentiate into CPCs and then transplanted in vivo, leading to not only an enhanced repair effect relative to WJMSC transplantation, but also avoidance of adverse consequences resulting from pluridirectional differentiation of stem cells as much as possible. At present, however, the experimental cost of WJMSCs is high, and WJMSCs do not appear to have outstanding advantages over other MSCs. Although there have been few relevant reports in recent years, it is undeniable that practical application of WJMSCs in the treatment of IDD has feasibility and potential.

\section{IVDSCs}

Previous studies demonstrated the existence of a certain number of MSCs, namely NPSCs, AFSCs, and CESCs, in the NP, AF, or CEPs of the IVD, which are collectively called IVDSCs. These cells share the characteristics of stem cell growth and differentiation, and thus have potential for IVD repair applications.

In an in vitro study, Wang et al. [86] compared the proliferation ability of BMSCs, NPSCs, AFSCs, and CESCs, and found that CESCs had the strongest ability for osteogenesis and chondrogenesis among these cell types. Other studies showed that CESCs can promote not only repair of CEPs, but also proliferation of NP cells through paracrine mechanisms [88]. NPSCs in NP tissues can migrate along the fibres and cells in the IVD [85]. Meanwhile, hypoxia can promote proliferation of NPSCs, which may be related to the HIF- $1 \alpha$ signal transduction pathway mediated by SIRT1 and SIRT6. Simvastatin can promote the expression of hypoxia-inducible factors and thus induce the differentiation of NPSCs into NP cells, achieving the effect of IVD repair [87] (Table 6).

Chen et al. [92] compared the in vivo therapeutic effect of NPSCs and NP cells transplanted into a rabbit IDD model, and found that the former had a better effect for IVD repair on imaging evaluation. Marimuthu et al. [93] isolated and amplified NP tissues from the IVD of normal mice, cultured NPSCs, and carried out allotransplantation. The results showed that NPSCs had good regenerative ability, and that this NP cell-based treatment led to enhanced anabolic activity of MSCs, while their catabolic activity was weakened. It was further found that NPSCs from allogeneic sources had a stronger stimulating effect on secretion of pro-inflammatory factors than NPSCs from homogeneic sources (Table 7).

At present, the application of IVDSCs faces great challenges. Although CESCs have the best repair effect, their efficiency for separation from CEPs is extremely low. In addition, it is difficult to specifically induce CESCs to differentiate into hyaline cartilage tissue. The microenvironment of the IVD is characterized by high pressure, high osmosis, low oxygen, low $\mathrm{pH}$, and insufficient nutrient supply, and the occurrence of IDD makes the microenvironment more severe. Furthermore, IVDSCs will age and undergo denaturation. These changing conditions pose a challenge to the viability of implanted stem cells.

\section{PSCs}

PSCs, with high capacities for self-renewal, proliferation, and differentiation, include IPSCs and ESCs. IPSCs are a special kind of cells generated by inducing the expression 
of ectopic recombinant transcription factors. For example, IPSCs derived from NP tissues can be induced to differentiate into NP-like chondrocytes that possess strong self-renewal, proliferation, and differentiation abilities. However, IPSCs are potentially tumorigenic. ESCs are pluripotent stem cells derived from discarded frozen early embryos. Currently, there are limited cell lines available for studies due to ethical issues. ESCs can differentiate into all derivatives of the three primary germ layers $[11,97]$.

In an in vitro study, Liu et al. [89] found that NP cells can secrete some regulatory factors that induce stem cells, and that these regulatory factors can promote differentiation of IPSCs into NP-like cells in the ECM, thus achieving the purpose of IVD repair. When GDF-5-transfected human IPSCs (GDF5-hIPSCs) were co-cultured with rat NP cells in vitro, the mRNA expression of three chondrocyte markers, SOX9, COL II, and proteoglycans, was significantly increased [90] (Table 6).

In an in vivo study, a GDF5-hIPSC hydrogel prepared by $\mathrm{Hu}$ et al. [90] was implanted into a rat IDD model. It was found that this complex gel effectively improved the symptoms of IDD by imaging and histological findings at 1,2 , and 3 months. When ESC-derived chondrocyte progenitors from mice were transplanted into the degenerative IVD of rabbits, NCs were successfully generated and proteoglycans were then produced by these NCs to promote IVD repair [94]. Use of MSCderived small extracellular vesicles (MSC-SEVs) is a novel strategy for the treatment of IDD. However, due to the disadvantages of MSCs, such as limited proliferation ability and invasive acquisition, the application and development of MSC-SEVs are limited. IMSCs derived from IPSCs can provide an abundant source of MSCSEVs. After injection of IMSC-SEVs into an IDD model, the senescence of NP cells was significantly delayed and the IDD status was obviously improved. IMSCSEVs rejuvenated the senescent NP cells and restored the age-related function by activating the SIRT6 pathway in vitro. Furthermore, microRNA sequence analysis showed that IMSC-SEVs were highly enriched in miR-105-5p, which had a pivotal role in the IMSCSEV-mediated therapeutic effect by downregulating the level of cAMP-specific hydrolase PDE4D and leading to SIRT6 activation [95] (Table 7).

Although PSCs can transform into the NP cell phenotype and promote repair in IDD, IPSCs have the characteristics of tumour cell proliferation and differentiation, and the directional differentiation of ESCs in vitro is unstable and inherently carcinogenic. These shortcomings as well as legal and ethical problems limit the further application of these two cell types (Fig. 3).

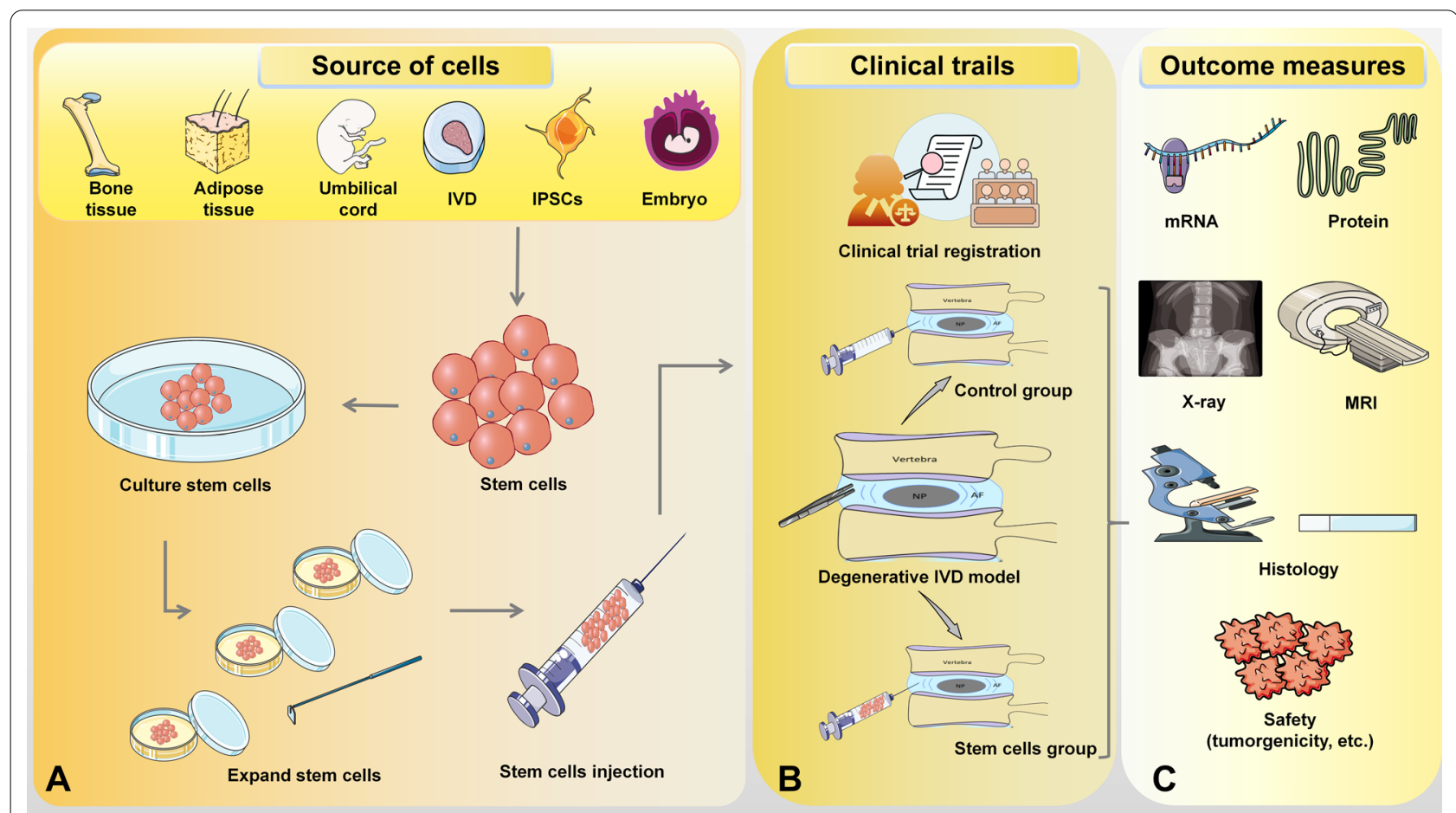

Fig. 3 Diagram of stem cell therapy for IVD degeneration. (A) Stem cell acquisition in vitro. (B) Stem cells and control group inject into degenerative IVD in vivo. (C) Tools to detect the role of stem cells in the degenerative disc. IPSCs induced pluripotent stem cells, IVD intervertebral disc 


\section{Defects in the application of stem cells}

Although many reports have demonstrated novel advantages of different stem cells in the treatment of IDD, other reports have described deficiencies in the application of stem cells. In addition to the disadvantages already mentioned, Coric et al. [98] found that cell injection therapy exceeding the normal range of cell dose was ineffective in delaying IDD or led to worse outcomes. Local injection of excessive numbers of cells may cause cell accumulation and death, thus triggering an inflammatory response. When injecting stem cells, the amount of injection is of great concern. Haufe et al. [99] used hematopoietic stem cells (HSCs) to conduct experiments on IDD in animal models and patients. While the animal experiments showed that the IVD could be regenerated by injection of HSCs, none of the ten patients had significantly improved symptoms of discogenic low back pain at the 6-month and 1-year follow-up visits. Therefore, the selection of stem cells plays a decisive role in the treatment of different subjects. Meisel et al. [8] analysed small case studies and found that stem cell therapy for patients with IDD may be useful in alleviating pain or improving IVD function, but the overall data on efficacy and safety did not reveal any major findings, and it was not clear whether the changes in symptoms were clinically important. Although the clinical efficacy was significant, there was a large risk of bias. In addition, at the stage of cell injection therapy, MSCs may undergo unnecessary cell migration or cell leakage after IVD injection, resulting in ineffective treatment and osteophyte formation [100]. Therefore, cell carriers and AF sealing technologies are particularly important. Certainly, an improper puncture operation can lead to disk infection or diskitis [101].

\section{Stem cell vectors in development}

In the application of stem cell transplantation, not only do the growth and differentiation degree of transplanted cells affect the therapeutic effect, but also the leakage of stem cells at the implantation site hinders the development of stem cells. Therefore, it is particularly important to control adverse cell migration and differentiation during IDD stem cell injection therapy. Many studies have shown that certain biomaterials can provide threedimensional structures suitable for stem cell growth to control undesirable migration, and can simultaneously be skilfully combined with biological factors or drugs that promote the differentiation of stem cells to NP cells, thereby promoting ECM secretion, inducing MSC differentiation to the NP cell phenotype, and accelerating IDD repair [91, 102, 103] (Fig. 4).

Vadala et al. [100] injected rabbit autologous BMSCs into an IDD model. They found no obvious IVD regeneration and no labelled MSCs in the IVD, but observed that the injected stem cells migrated to the outside of the IVD and formed undesirable osteophytes. To solve such adverse problems, researchers have considered

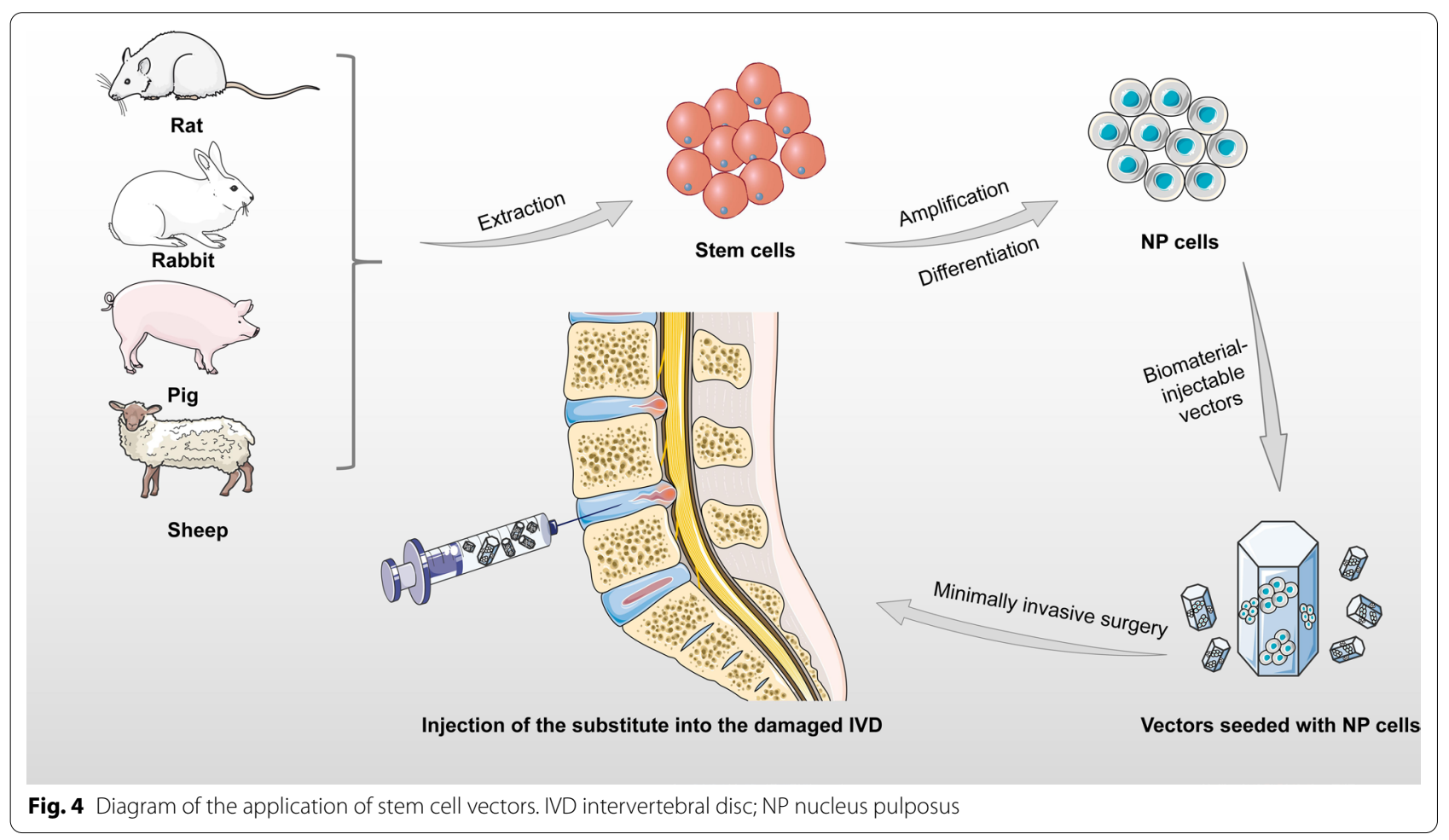


different approaches, such as the co-culture stage, drugloaded injection, and cell differentiation stage in vivo, to combine stem cells with different vectors that avoid the occurrence of adverse reactions, and ensure that stem cells can continue to play a stable, efficient, and accurate role.

BMSCs embedded in alginate microcapsules were implanted into the NP of the bovine IVD in vitro after low temperature and low oxygen disposal, and this coculture was found to lead to increased production of ECM components [104]. Co-culture of mouse BMSCs with glucose-gelatine hydrogel scaffold-loaded TGF- $\beta 3$ effectively induced the differentiation of BMSCs into NP cells and promoted the expression of ECM-related genes [105]. When microencapsulated rabbit chondrocytes were co-cultured with BMSCs, the activity of BMSCs and the expression of COL II and proteoglycans were detected. The microcapsule co-culture system not only had no effect on the function of BMSCs, but also increased the production of COL II and proteoglycans. At the same time, an in vivo experiment showed that the repair effect in the co-culture group was significantly better than that in the monoculture BMSC group [106]. The functional self-assembled peptide nanofibre scaffold prepared by Wu et al. [107] was proven to promote the differentiation, proliferation, and chemotactic migration of BMSCs to NP cells in experiments. Kuang et al. [108] cultured NPSCs into a hydrogel scaffold made of acellular NP matrix and chitosan, and then added TGF- $\beta 3$. Compared with the simple hydrogel group, NPSCs grew better in the mixed hydrogel group containing growth factors, and the COL I, COL II, and proteoglycan genes were more strongly expressed. An HA-methylcellulose hydrogel system loaded with WJMSCs was implanted into a rat IDD model. Compared with WJMSCs alone, the combined group had a stronger IVD repair effect by improving the viability of NP cells and reducing the degradation of ECM [109]. There is also a hot spot in current research for loading drugs into the body through carriers and producing corresponding effects on stem cells. For example, injection of albumin/heparin nanoparticles loaded with stromal cell-derived factor SDF- $1 \alpha$ into an IDD model induced IVD regeneration and enhanced the homing ability of BMSCs [110] (Table 9).

Table 9 The application of Stem Cell Vectors

\begin{tabular}{|c|c|c|c|c|}
\hline Year & Team & Source of stem cells and vectors & Model & Results \\
\hline 2016 & Gan et al. [105] & $\begin{array}{l}\text { Glucose-gelatin hydrogel scaffold-loaded } \\
\text { TGF- } \beta 3+\text { mouse BMSCs }\end{array}$ & In vitro & $\begin{array}{l}\text { BMSCs differentiate into NP cells, ECM gene } \\
\text { expression } \uparrow\end{array}$ \\
\hline 2016 & Wu et al. [107] & $\begin{array}{l}\text { Self-assembled peptide nanofiber scaf- } \\
\text { fold + rabbit BMSCs + rabbit chondrocytes }\end{array}$ & Rabbit IDD model & $\begin{array}{l}\text { Promote BMSCs differentiating into NP cells, } \\
\text { promote BMSCs proliferation and chemot- } \\
\text { actic migration }\end{array}$ \\
\hline 2018 & Zhang et al. [106] & $\begin{array}{l}\text { Microencapsulated rabbit chondro- } \\
\text { cytes + rabbit BMSCs }\end{array}$ & Rabbit IDD model & $\begin{array}{l}\text { The combination system do not affect the } \\
\text { function of BMSCs, COL II and proteoglycan } \\
\text { content } \uparrow \text {, the repair effect of co-culture } \\
\text { group perform better than the original } \\
\text { BMSCs group }\end{array}$ \\
\hline 2018 & Zhang et al. [110] & $\begin{array}{l}\text { Albumin/heparin nanoparticles loaded } \\
\text { with SDF-1a }\end{array}$ & Rabbit IDD model & $\begin{array}{l}\text { Induce IVD regeneration, enhance the hom- } \\
\text { ing ability of BMSCs }\end{array}$ \\
\hline 2018 & Zhou et al. [74] & $\begin{array}{l}\text { Human ADMSCs loaded in pig acellular } \\
\text { NP scaffolds }\end{array}$ & Rabbit IDD model & $\begin{array}{l}\mathrm{ECM} \uparrow \text {, the mechanical properties and bio- } \\
\text { compatibility of the combination system are } \\
\text { brilliant, ADMSCs differentiate into NP cells }\end{array}$ \\
\hline 2019 & Hussain et al. [51] & $\begin{array}{l}\text { Allogeneic sheep BMSCs loaded in acel- } \\
\text { lular high-density collagen gel }\end{array}$ & Sheep IDD model with AF injured & $\begin{array}{l}\text { DHI, Pfirmann grade, NP area all perform } \\
\text { well in } 6 \text { weeks, AF and NP tissue improve } \\
\text { in histology }\end{array}$ \\
\hline 2019 & Naqvi et al. [104] & $\begin{array}{l}\text { Pig BMSCs embedded in alginate micro- } \\
\text { capsules }\end{array}$ & Bovine IVD model & $\mathrm{ECM} \uparrow$ \\
\hline 2019 & Ishiguro et al. [75] & $\begin{array}{l}\text { Stent-free tissue engineering structure } \\
\text { made by ADMSCs }\end{array}$ & Rat IDD model without NP & $\begin{array}{l}\text { Biomechanical properties are maintained, } \\
\text { IVD height maintain, AF and CEPs retain }\end{array}$ \\
\hline 2020 & Choi et al. [109] & $\begin{array}{l}\text { WJMSCs loaded in hyaluronic acid-methyl- } \\
\text { cellulose hydrogel system }\end{array}$ & Rat IDD model & $\begin{array}{l}\text { Improve the viability of NP cells, reduce ECM } \\
\text { degradation }\end{array}$ \\
\hline 2021 & Kuang et al. [108] & $\begin{array}{l}\text { Acellular NP matrix and chitosan hydrogel } \\
\text { scaffold + TGF- } \beta 3+\text { NPSCs }\end{array}$ & In vitro & $\begin{array}{l}\text { NPSCs grow better in scaffold group, COL } \\
\text { I,COL II and proteoglycan content } \uparrow\end{array}$ \\
\hline
\end{tabular}

ADMSCs adipose mesenchymal stem cells, AF annulus fibrosus, BMSCs bone marrow mesenchymal stem cells, CEPs cartilaginous endplates, COL I collagen type I, COL II collagen type II, DHI disc height index, ECM extracellular matrix, IDD intervertebral disc degeneration, IVD intervertebral disc, NP nucleus pulposus, NPSCs nucleus pulposus stem cells, SDF stromal cell-derived factor, TGF transforming growth factor, WJMSCs Wharton's Jelly mesenchymal stem cells 


\section{Conclusions}

Whether examined in vitro, in animals, or in clinical trials, stem cell therapy for DDDs has been proven to show promise in different aspects. Stem cells from different sources have different degrees of ability to induce differentiation, produce different biological effects, and promote the expression of different biological factors. With the deepening of stem cell research, our understanding of stem cell therapy for IDD has improved. Meanwhile, the indications for stem cell therapy for IDD have gradually expanded, and the sources of stem cells have been enriched, laying a solid foundation for the experimental and clinical application of stem cell therapy for IDD.

Although cell therapy appears to have great potential for IVD regeneration, there remains a lack of relevant evidence regarding safety, long-term complications, effectiveness in different patient populations, and surgical cost-effectiveness. Further development of stem cell technology and in-depth exploration of IDD in the medical community will determine the future development direction of the organic combination of stem cells and IDD research. First, we need to further explore the interactions between stem cell repair mechanisms and target cells, and strive to identify more targets that promote differentiation. Second, we need to find ways to improve the harsh microenvironment in IDD to provide a better living environment for loaded stem cells. Third, we need to establish methods that can induce and differentiate stem cells from different sources more efficiently and stably, thereby improving the safety of stem cell application. Last, but not the least, it is necessary to optimize the performance of stem cell carrier materials to avoid secondary damage during implantation and further enhance the repair ability of stem cells.

\begin{abstract}
Abbreviations
ACAN: Aggrecan; ADMSCs: Adipose mesenchymal stem cells; AF: Annulus fibrosus; AFSCs: Annulus fibrosus stem cells; BMP: Bone morphogenetic protein; BMSCs: Bone marrow mesenchymal stem cells; CEPs: Cartilaginous endplates; CESCs: Cartilage endplate stem cells; COL I: Collagen type I; CPCs: Chondrogenic progenitor cells; DDDs: Degenerative disc diseases; DHI: Disc height index; ECM: Extracellular matrix; EPO: Erythropoietin; ESCs: Embryonic stem cells; Exos: Exsomes; GDF: Growth differentiation factor; GDF-5-hIPSCs: GDF-5-transfected human IPSCs; HA: Hyaluronic acid; hTIMP: Metalloproteinase tissue inhibitor; IDD: Intervertebral disc degeneration; IFN: Interferon; IL: Interleukin; IPSCs: Induced pluripotent stem cells; IVD: Intervertebral disc; IVDSCs: Intervertebral-derived stem cells; MAPK: Mitogen activated protein kinase; MMPs: Matrix metalloproteinases; MSCs: Mesenchymal stem cells; MSCs-SEVs: Derived small extracellular vesicles; NCs: Notochord cells; NP: Nucleus pulposus; NPSCs: Nucleus pulposus stem cells; PGE: Prostaglandin E; PSCs: Pluripotent stem cells; SAG: Smoothened agonist; Shh: Sonic hedgehog; TBT: Transgenic BMSCs; TEC: Tissue engineering structure; TNF: Tumor necrosis factor; UCMSCs: Umbilical cord mesenchymal stem cells; WJMSCs: Wharton's Jelly mesenchymal stem cells.
\end{abstract}

Acknowledgements

We would like to thank all the participants in the study.

\section{Authors' contributions}

All authors contributed to the conception and the main idea of the work. WTZ drafted the main text, tables and figures. YL and MY supervised the work, and provided additional scientific information. TZS revised the tables and figures. $Y T Z, J L$ and $Z H L$ reviewed and revised the text. All authors read and approved the final manuscript.

\section{Funding}

This study was supported by LiaoNing Revitalization Talents Program (XLYC1807131), the Science and Technology Innovation Foundation of Dalian (2020JJ27SN070) and the open project of Key Laboratory for Micro/Nano Technology and System of Liaoning Province, Dalian University of Technology (20210101). The funders had no role in the study design, data collection and analysis, decision to publish, or preparation of the manuscript.

\section{Availability of data and materials}

Not applicable.

\section{Declarations}

Ethics approval and consent to participate

Not applicable.

\section{Consent for publication}

Not applicable.

\section{Competing interests}

The authors declare that they have no competing interests.

\section{Author details}

${ }^{1}$ Department of Orthopedics, First Affiliated Hospital of Dalian Medical University, Dalian, People's Republic of China. ${ }^{2}$ Key Laboratory of Molecular Mechanism for Repair and Remodeling of Orthopedic Diseases, Dalian, People's Republic of China. ${ }^{3}$ Department of Orthopedics, Fourth Medical Center of PLA General Hospital, Beijing, People's Republic of China. ${ }^{4}$ Stem Cell Clinical Research Center, National Joint Engineering Laboratory, First Affiliated Hospital of Dalian Medical University, Dalian, People's Republic of China. ${ }^{5}$ Dalian Innovation Institute of Stem Cell and Precision Medicine, Dalian, People's Republic of China.

Received: 16 October 2021 Accepted: 25 January 2022

Published online: 11 February 2022

\section{References}

1. Battié MC, Joshi AB, Gibbons LE. Degenerative disc disease: What is in a name? Spine (Phila Pa 1976). 2019:44(21):1523-9.

2. Pan M, Li Q, Li S, Mao H, Meng B, Zhou F, et al. Percutaneous endoscopic lumbar discectomy: indications and complications. Pain Physician. 2020;23(1):49-56.

3. Kim HS, Raorane HD, Wu PH, Heo DH, Sharma SB, Jang IT. Incidental durotomy during endoscopic stenosis lumbar decompression: incidence, classification, and proposed management strategies. World Neurosurg. 2020;139:e13-22.

4. Yörükoğlu AG, Göker B, Tahta A, Akçakaya MO, Aydoseli A, Sabancı $\mathrm{PA}$, et al. Fully endoscopic interlaminar and transforaminal lumbar discectomy: analysis of 47 complications encountered in a series of 835 patients. Neurocirugia (Astur). 2017;28(5):235-41.

5. Sugimoto N, Eto K. Platelet production from induced pluripotent stem cells. J Thromb Haemost. 2017;15(9):1717-27.

6. Boese AC, Hamblin MH, Lee JP. Neural stem cell therapy for neurovascular injury in Alzheimer's disease. Exp Neurol. 2020;324:113112.

7. Pietrosi G, Fernández-Iglesias A, Pampalone M, Ortega-Ribera M, Lozano JJ, García-Calderó H, et al. Human amniotic stem cells improve hepatic microvascular dysfunction and portal hypertension in cirrhotic rats. Liver Int. 2020;40(10):2500-14.

8. Meisel HJ, Agarwal N, Hsieh PC, Skelly A, Park JB, Brodke D, et al. Cell therapy for treatment of intervertebral disc degeneration: a systematic review. Glob Spine J. 2019;9(1 Suppl):39s-52s. 
9. Croft AS, Illien-Jünger S, Grad S, Guerrero J, Wangler S, Gantenbein B. The application of mesenchymal stromal cells and their homing capabilities to regenerate the intervertebral disc. Int J Mol Sci. 2021;22(7):3519

10. Richardson SM, Kalamegam G, Pushparaj PN, Matta C, Memic A, Khademhosseini $A$, et al. Mesenchymal stem cells in regenerative medicine: focus on articular cartilage and intervertebral disc regeneration. Methods. 2016;99:69-80.

11. Gou S, Oxentenko SC, Eldrige JS, Xiao L, Pingree MJ, Wang Z, et al. Stem cell therapy for intervertebral disk regeneration. Am J Phys Med Rehabil. 2014;93(11 Suppl 3):S122-131.

12. Silverman LI, Dulatova G, Tandeski T, Erickson IE, Lundell B, Toplon D, et al. In vitro and in vivo evaluation of discogenic cells, an investigational cell therapy for disc degeneration. Spine J. 2020;20(1):138-49.

13. Dowdell J, Erwin M, Choma T, Vaccaro A, latridis J, Cho SK. Intervertebral Disk degeneration and repair. Neurosurgery. 2017;80(3s):S46-s54.

14. Ohtori S, Inoue G, Miyagi M, Takahashi K. Pathomechanisms of discogenic low back pain in humans and animal models. Spine J. 2015;15(6):1347-55.

15. Chang Y, Yang M, Ke S, Zhang Y, Xu G, Li Z. Effect of platelet-rich plasma on intervertebral disc degeneration in vivo and in vitro: a critical review. Oxid Med Cell Longev. 2020;2020:8893819.

16. Takahashi H, Suguro T, Okazima Y, Motegi M, Okada Y, Kakiuchi T. Inflammatory cytokines in the herniated disc of the lumbar spine. Spine (Phila Pa 1976). 1996;21(2):218-24.

17. Miyamoto H, Saura R, Doita M, Kurosaka M, Mizuno K. The role of cyclooxygenase-2 in lumbar disc herniation. Spine (Phila Pa 1976). 2002;27(22):2477-83.

18. Feng C, Liu H, Yang M, Zhang Y, Huang B, Zhou Y. Disc cell senescence in intervertebral disc degeneration: causes and molecular pathways. Cell Cycle. 2016:15(13):1674-84.

19. Beall DP, Wilson GL, Bishop R, Tally W. VAST clinical trial: safely supplementing tissue lost to degenerative disc disease. Int I Spine Surg. 2020;14(2):239-53.

20. Urits I, Capuco A, Sharma M, Kaye AD, Viswanath O, Cornett EM, et al. Stem cell therapies for treatment of discogenic low back pain: a comprehensive review. Curr Pain Headache Rep. 2019;23(9):65.

21. Weng Z, Zhang B, Wu C, Yu F, Han B, Li B, et al. Therapeutic roles of mesenchymal stem cell-derived extracellular vesicles in cancer. J Hematol Oncol. 2021;14(1):136.

22. Ajit A, Ambika Gopalankutty I. Adipose-derived stem cell secretome as a cell-free product for cutaneous wound healing. 3 Biotech. 2021;11(9):413.

23. Subramaniam MD, Kumar BA, lyer M, Vellingiri B. Leber's hereditary optic neuropathy: current approaches and future perspectives on mesenchymal stem cell-mediated rescue. Mitochondrion. 2021;60:201-18.

24. Nouri N, Aghebati-Maleki L, Yousefi M. Adipose-derived mesenchymal stem cells: a promising tool in the treatment of pre mature ovarian failure. J Reprod Immunol. 2021:147:103363.

25. Le Maitre CL, Baird P, Freemont AJ, Hoyland JA. An in vitro study investigating the survival and phenotype of mesenchymal stem cells following injection into nucleus pulposus tissue. Arthritis Res Ther. 2009:11(1):R20

26. Sakai D, Mochida J, Iwashina T, Watanabe T, Nakai T, Ando K, et al. Differentiation of mesenchymal stem cells transplanted to a rabbit degenerative disc model: potential and limitations for stem cell therapy in disc regeneration. Spine (Phila Pa 1976). 2005;30(21):2379-87.

27. Richardson SM, Walker RV, Parker S, Rhodes NP, Hunt JA, Freemont AJ, et al. Intervertebral disc cell-mediated mesenchymal stem cell differentiation. Stem Cells. 2006:24(3):707-16.

28. Vadalà G, Studer RK, Sowa G, Spiezia F, lucu C, Denaro V, et al. Coculture of bone marrow mesenchymal stem cells and nucleus pulposus cells modulate gene expression profile without cell fusion. Spine (Phila Pa 1976). 2008:33(8):870-6.

29. Vadalà G, Sobajima S, Lee JY, Huard J, Denaro V, Kang JD, et al. In vitro interaction between muscle-derived stem cells and nucleus pulposus cells. Spine J. 2008;8(5):804-9.

30. Chen S, Zhao L, Deng X, Shi D, Wu F, Liang H, et al. Mesenchymal stem cells protect nucleus pulposus cells from compression-induced apoptosis by inhibiting the mitochondrial pathway. Stem Cells Int. 2017:2017:9843120.
31. Liu MH, Bian BS, Cui X, Liu LT, Liu H, Huang B, et al. Mesenchymal stem cells regulate mechanical properties of human degenerated nucleus pulposus cells through SDF-1/CXCR4/AKT axis. Biochim Biophys Acta. 2016;1863(8):1961-8.

32. James G, Blomster L, Hall L, Schmid AB, Shu CC, Little CB, et al. Mesenchymal stem cell treatment of intervertebral disc lesion prevents fatty infiltration and fibrosis of the multifidus muscle, but not cytokine and muscle fiber changes. Spine (Phila Pa 1976). 2016;41(15):1208-17.

33. Borem R, Madeline A, Bowman M, Gill S, Tokish J, Mercuri J. Differential effector response of amnion- and adipose-derived mesenchymal stem cells to inflammation; implications for intradiscal therapy. J Orthop Res. 2019;37(11):2445-56

34. Lyu FJ, Cheung KM, Zheng Z, Wang H, Sakai D, Leung VY. IVD progenitor cells: a new horizon for understanding disc homeostasis and repair. Nat Rev Rheumatol. 2019;15(2):102-12.

35. Teixeira GQ, Pereira CL, Ferreira JR, Maia AF, Gomez-Lazaro M, Barbosa $M A$, et al. Immunomodulation of human mesenchymal stem/ stromal cells in intervertebral disc degeneration: insights from a proinflammatory/degenerative ex vivo model. Spine (Phila Pa 1976). 2018:43(12):E673-e682.

36. Wangler S, Peroglio M, Menzel U, Benneker LM, Haglund L, Sakai $D$, et al. Mesenchymal stem cell homing into intervertebral discs enhances the Tie2-positive progenitor cell population, prevents cell death, and induces a proliferative response. Spine (Phila Pa 1976). 2019:44(23):1613-22.

37. Zhan J, He J, Chen M, Luo D, Lin D. Fasudil promotes BMSC migration via activating the MAPK signaling pathway and application in a model of spinal cord injury. Stem Cells Int. 2018;2018:9793845.

38. Xu J, E XQ, Wang NX, Wang MN, Xie HX, Cao YH, et al. BMP enhances the effect of BMSCs on extracellular matrix remodeling in a rabbit model of intervertebral disc degeneration. Febs J. 2016;283(9):1689-700.

39. Zhou X, Tao Y, Liang C, Zhang Y, Li H, Chen Q. BMP3 alone and together with TGF- $\beta$ promote the differentiation of human mesenchymal stem cells into a nucleus pulposus-like phenotype. Int J Mol Sci. 2015;16(9):20344-59.

40. Han C, Jiang C, Yu C, Shen H. Differentiation of transforming growth factor $\beta 1$-induced mesenchymal stem cells into nucleus pulposus-like cells under simulated microgravity conditions. Cell Mol Biol (Noisy-legrand). 2015;61 (2):50-5.

41. Sakai D, Mochida J, Yamamoto Y, Nomura T, Okuma M, Nishimura K, et al. Transplantation of mesenchymal stem cells embedded in Atelocollagen gel to the intervertebral disc: a potential therapeutic model for disc degeneration. Biomaterials. 2003;24(20):3531-41.

42. Cao C, Zou J, Liu X, Shapiro A, Moral M, Luo Z, et al. Bone marrow mesenchymal stem cells slow intervertebral disc degeneration through the NF-KB pathway. Spine J. 2015;15(3):530-8.

43. Zhou Y, Hu X, Zheng X, Wu Y, Tian N, Xu H, et al. Differentiation potential of mesenchymal stem cells derived from adipose tissue vs bone marrow toward annulus fibrosus cells in vitro. Curr Stem Cell Res Ther. 2017;12(5):432-9.

44. Li X, Wu A, Han C, Chen C, Zhou T, Zhang K, et al. Bone marrowderived mesenchymal stem cells in three-dimensional co-culture attenuate degeneration of nucleus pulposus cells. Aging (Albany NY). 2019;11(20):9167-87.

45. Yang H, Tian W, Wang S, Liu X, Wang Z, Hou L, et al. TSG-6 secreted by bone marrow mesenchymal stem cells attenuates intervertebral disc degeneration by inhibiting the TLR2/NF-KB signaling pathway. Lab Investig. 2018;98(6):755-72.

46. Lehmann TP, Filipiak K, Juzwa W, Sujka-Kordowska P, Jagodziński PP, Zabel $\mathrm{M}$, et al. Co-culture of human nucleus pulposus cells with multipotent mesenchymal stromal cells from human bone marrow reveals formation of tunnelling nanotubes. Mol Med Rep. 2014;9(2):574-82.

47. Lu K, Li HY, Yang K, Wu JL, Cai XW, Zhou Y, et al. Exosomes as potential alternatives to stem cell therapy for intervertebral disc degeneration: in-vitro study on exosomes in interaction of nucleus pulposus cells and bone marrow mesenchymal stem cells. Stem Cell Res Ther. 2017:8(1):108.

48. Cheng X, Zhang G, Zhang L, Hu Y, Zhang K, Sun X, et al. Mesenchymal stem cells deliver exogenous miR-21 via exosomes to inhibit nucleus pulposus cell apoptosis and reduce intervertebral disc degeneration. J Cell Mol Med. 2018;22(1):261-76. 
49. Xia C, Zeng Z, Fang B, Tao M, Gu C, Zheng L, et al. Mesenchymal stem cell-derived exosomes ameliorate intervertebral disc degeneration via anti-oxidant and anti-inflammatory effects. Free Radic Biol Med. 2019;143:1-15.

50. Sakai D, Mochida J, Iwashina T, Hiyama A, Omi H, Imai M, et al. Regenerative effects of transplanting mesenchymal stem cells embedded in atelocollagen to the degenerated intervertebral disc. Biomaterials. 2006;27(3):335-45.

51. Hussain I, Sloan SR, Wipplinger C, Navarro-Ramirez R, Zubkov M, Kim $E$, et al. Mesenchymal stem cell-seeded high-density collagen gel for annular repair: 6-week results from in vivo sheep models. Neurosurgery. 2019;85(2):E350-e359.

52. Yan HS, Hang C, Chen SW, Wang KK, Bo P. Salvianolic acid B combined with mesenchymal stem cells contributes to nucleus pulposus regeneration. Connect Tissue Res. 2020;61(5):435-44

53. Lykov AP, Bondarenko NA, Poveshchenko OV, Kim II, Surovtseva MA, Sadykova JB, et al. Treatment of intervertebral disc degeneration in Wistar rats with mesenchymal stem cells. Bull Exp Biol Med. 2020;168(4):578-82

54. Yi Z, Guanjun T, Lin C, Zifeng P. Effects of transplantation of hTIMP-1-expressing bone marrow mesenchymal stem cells on the extracellular matrix of degenerative intervertebral discs in an in vivo rabbit model. Spine. 2014;39(11):E669-e675

55. Shi P, Chee A, Liu W, Chou PH, Zhu J, An HS. Therapeutic effects of cell therapy with neonatal human dermal fibroblasts and rabbit dermal fibroblasts on disc degeneration and inflammation. Spine J. 2019;19(1):171-81.

56. Orozco L, Soler R, Morera C, Alberca M, Sánchez A, García-Sancho J. Intervertebral disc repair by autologous mesenchymal bone marrow cells: a pilot study. Transplantation. 2011;92(7):822-8.

57. Mochida J, Sakai D, Nakamura Y, Watanabe T, Yamamoto Y, Kato S. Intervertebral disc repair with activated nucleus pulposus cell transplantation: a three-year, prospective clinical study of its safety. Eur Cell Mater. 2015;29:202-12 (discussion 212).

58. Elabd C, Centeno CJ, Schultz JR, Lutz G, Ichim T, Silva FJ. Intra-discal injection of autologous, hypoxic cultured bone marrow-derived mesenchymal stem cells in five patients with chronic lower back pain: a long-term safety and feasibility study. J Transl Med. 2016;14(1):253.

59. Centeno C, Markle J, Dodson E, Stemper I, Williams CJ, Hyzy M, et al. Treatment of lumbar degenerative disc disease-associated radicular pain with culture-expanded autologous mesenchymal stem cells: a pilot study on safety and efficacy. J Transl Med. 2017;15(1):197.

60. Pettine KA, Suzuki RK, Sand TT, Murphy MB. Autologous bone marrow concentrate intradiscal injection for the treatment of degenerative disc disease with three-year follow-up. Int Orthop. 2017;41(10):2097-103.

61. Henriksson HB, Papadimitriou N, Hingert D, Baranto A, Lindahl A, Brisby $H$. The traceability of mesenchymal stromal cells after injection into degenerated discs in patients with low back pain. Stem Cells Dev. 2019;28(17):1203-11.

62. Noriega DC, Ardura F, Hernández-Ramajo R, Martín-Ferrero M, SánchezLite I, Toribio B, et al. Intervertebral disc repair by allogeneic mesenchymal bone marrow cells: a randomized controlled trial. Transplantation. 2017:101(8):1945-51.

63. Vasiliadis ES, Pneumaticos SG, Evangelopoulos DS, Papavassiliou AG. Biologic treatment of mild and moderate intervertebral disc degeneration. Mol Med. 2014;20(1):400-9.

64. Marfia G, Campanella R, Navone SE, Zucca I, Scotti A, Figini M, et al. Potential use of human adipose mesenchymal stromal cells for intervertebral disc regeneration: a preliminary study on biglycandeficient murine model of chronic disc degeneration. Arthritis Res Ther. 2014;16(5):457.

65. Diekman BO, Rowland CR, Lennon DP, Caplan Al, Guilak F. Chondrogenesis of adult stem cells from adipose tissue and bone marrow: induction by growth factors and cartilage-derived matrix. Tissue Eng Part A. 2010;16(2):523-33.

66. Jin ES, Min J, Jeon SR, Choi KH, Jeong JH. Analysis of molecular expression in adipose tissue-derived mesenchymal stem cells: prospects for use in the treatment of intervertebral disc degeneration. J Korean Neurosurg Soc. 2013;53(4):207-12.

67. Clarke LE, MCConnell JC, Sherratt MJ, Derby B, Richardson SM, Hoyland JA. Growth differentiation factor 6 and transforming growth factor-beta differentially mediate mesenchymal stem cell differentiation, composition, and micromechanical properties of nucleus pulposus constructs. Arthritis Res Ther. 2014;16(2):R67.

68. Lu ZF, Doulabi BZ, Wuisman PI, Bank RA, Helder MN. Influence of collagen type II and nucleus pulposus cells on aggregation and differentiation of adipose tissue-derived stem cells. J Cell Mol Med. 2008;12(6b):2812-22.

69. Dai X, Guan Y, Zhang Z, Xiong Y, Liu C, Li H, et al. Comparison of the differentiation abilities of bone marrow-derived mesenchymal stem cells and adipose-derived mesenchymal stem cells toward nucleus pulposus-like cells in three-dimensional culture. Exp Ther Med. 2021;22(3):1018.

70. Han Z, Wang J, Gao L, Wang Q, Wu J. Aberrantly expressed messenger RNAs and long noncoding RNAs in degenerative nucleus pulposus cells co-cultured with adipose-derived mesenchymal stem cells. Arthritis Res Ther. 2018;20(1):182.

71. Sun Z, Luo B, Liu ZH, Samartzis D, Liu Z, Gao B, et al. Adipose-derived stromal cells protect intervertebral disc cells in compression: implications for stem cell regenerative disc therapy. Int J Biol Sci. 2015:11(2):133-43.

72. Han Z, Wang Q, Wu X, Wang J, Gao L, Guo R, et al. Comprehensive RNA expression profile of therapeutic adipose-derived mesenchymal stem cells co-cultured with degenerative nucleus pulposus cells. Mol Med Rep. 2021. https://doi.org/10.3892/mmr.2021.11824.

73. Ganey T, Hutton WC, Moseley T, Hedrick M, Meisel HJ. Intervertebral disc repair using adipose tissue-derived stem and regenerative cells: experiments in a canine model. Spine (Phila Pa 1976). 2009:34(21):2297-304.

74. Zhou X, Wang J, Huang X, Fang W, Tao Y, Zhao T, et al. Injectable decellularized nucleus pulposus-based cell delivery system for differentiation of adipose-derived stem cells and nucleus pulposus regeneration. Acta Biomater. 2018:81:115-28.

75. Ishiguro H, Kaito T, Yarimitsu S, Hashimoto K, Okada R, Kushioka J, et al. Intervertebral disc regeneration with an adipose mesenchymal stem cell-derived tissue-engineered construct in a rat nucleotomy model. Acta Biomater. 2019;87:118-29.

76. Hua J, Shen N, Wang J, Tao Y, Li F, Chen Q, et al. Small Molecule-based strategy promotes nucleus pulposus specific differentiation of adiposederived mesenchymal stem cells. Mol Cells. 2019:42(9):661-71.

77. Kumar H, Ha DH, Lee EJ, Park JH, Shim JH, Ahn TK, et al. Safety and tolerability of intradiscal implantation of combined autologous adiposederived mesenchymal stem cells and hyaluronic acid in patients with chronic discogenic low back pain: 1-year follow-up of a phase I study. Stem Cell Res Ther. 2017;8(1):262.

78. Xie L, Lin L, Tang Q, Li W, Huang T, Huo X, et al. Sertoli cell-mediated differentiation of male germ cell-like cells from human umbilical cord Wharton's jelly-derived mesenchymal stem cells in an in vitro coculture system. Eur J Med Res. 2015;20(1):9.

79. Garzón I, Martín-Piedra MA, Alfonso-Rodríguez C, González-Andrades M, Carriel V, Martínez-Gómez C, et al. Generation of a biomimetic human artificial cornea model using Wharton's jelly mesenchymal stem cells. Investig Ophthalmol Vis Sci. 2014;55(7):4073-83.

80. Chen H, Zhang Y, Yang Z, Zhang H. Human umbilical cord Wharton's jelly-derived oligodendrocyte precursor-like cells for axon and myelin sheath regeneration. Neural Regen Res. 2013;8(10):890-9.

81. Wang $Q$, Yang $Q$, Wang Z, Tong $H$, Ma L, Zhang Y, et al. Comparative analysis of human mesenchymal stem cells from fetal-bone marrow, adipose tissue, and Warton's jelly as sources of cell immunomodulatory therapy. Hum Vaccin Immunother. 2016;12(1):85-96.

82. Beeravolu N, Brougham J, Khan I, McKee C, Perez-Cruet M, Chaudhry GR. Human umbilical cord derivatives regenerate intervertebral disc. J Tissue Eng Regen Med. 2018;12(1):e579-91.

83. Qi L, Wang R, Shi Q, Yuan M, Jin M, Li D. Umbilical cord mesenchymal stem cell conditioned medium restored the expression of collagen II and aggrecan in nucleus pulposus mesenchymal stem cells exposed to high glucose. J Bone Miner Metab. 2019;37(3):455-66.

84. Zhao YT, Qin Y, Yang JS, Huang DG, Hu HM, Wang XD, et al. Wharton's Jelly-derived mesenchymal stem cells suppress apoptosis of nucleus pulposus cells in intervertebral disc degeneration via Wnt pathway. Eur Rev Med Pharmacol Sci. 2020;24(19):9807-14.

85. Barreto Henriksson H, Lindahl A, Skioldebrand E, Junevik K, Tängemo C, Mattsson J, et al. Similar cellular migration patterns from niches in 
intervertebral disc and in knee-joint regions detected by in situ labeling: an experimental study in the New Zealand white rabbit. Stem Cell Res Ther. 2013;4(5):104.

86. Wang H, Zhou Y, Chu TW, Li CQ, Wang J, Zhang ZF, et al. Distinguishing characteristics of stem cells derived from different anatomical regions of human degenerated intervertebral discs. Eur Spine J. 2016;25(9):2691-704.

87. Huang Z, Zhang L, Feng X, Chen T, Bi S. A new in vivo method to retard progression of intervertebral disc degeneration through stimulation of endogenous stem cells with simvastatin. Med Hypotheses. 2017:101:65-6.

88. He Z, Jia M, Yu Y, Yuan C, Wang J. Roles of SDF-1/CXCR4 axis in cartilage endplate stem cells mediated promotion of nucleus pulposus cells proliferation. Biochem Biophys Res Commun. 2018:506(1):94-101.

89. Liu Y, Fu S, Rahaman MN, Mao JJ, Bal BS. Native nucleus pulposus tissue matrix promotes notochordal differentiation of human induced pluripotent stem cells with potential for treating intervertebral disc degeneration. J Biomed Mater Res A. 2015;103(3):1053-9.

90. Hu A, Xing R, Jiang L, Li Z, Liu P, Wang H, et al. Thermosensitive hydrogels loaded with human-induced pluripotent stem cells overexpressing growth differentiation factor-5 ameliorate intervertebral disc degeneration in rats. J Biomed Mater Res B Appl Biomater. 2020;108(5):2005-16.

91. McKee C, Beeravolu N, Brown C, Perez-Cruet M, Chaudhry GR. Mesenchymal stem cells transplanted with self-assembling scaffolds differentiated to regenerate nucleus pulposus in an ex vivo model of degenerative disc disease. Appl Mater Today. 2020;18:100474.

92. Chen X, Zhu L, Wu G, Liang Z, Yang L, Du Z. A comparison between nucleus pulposus-derived stem cell transplantation and nucleus pulposus cell transplantation for the treatment of intervertebral disc degeneration in a rabbit model. Int J Surg. 2016;28:77-82.

93. Marimuthu C, Pushpa Rani V. Elucidating the role of cell-mediated inflammatory cytokines on allogeneic mouse-derived nucleus pulposus mesenchymal stem cells. J Food Biochem. 2021;45(4):e13681.

94. Sheikh H, Zakharian K, De La Torre RP, Facek C, Vasquez A, Chaudhry GR, et al. In vivo intervertebral disc regeneration using stem cell-derived chondroprogenitors. J Neurosurg Spine. 2009;10(3):265-72.

95. Sun Y, Zhang W, Li X. Induced pluripotent stem cell-derived mesenchymal stem cells deliver exogenous miR-105-5p via small extracellular vesicles to rejuvenate senescent nucleus pulposus cells and attenuate intervertebral disc degeneration. Stem Cell Res Ther. 2021:12(1):286.

96. Pang $X$, Yang $H$, Peng B. Human umbilical cord mesenchymal stem cell transplantation for the treatment of chronic discogenic low back pain. Pain Physician. 2014;17(4):E525-530.

97. Thomson JA, Itskovitz-Eldor J, Shapiro SS, Waknitz MA, Swiergiel J Marshall VS, et al. Embryonic stem cell lines derived from human blastocysts. Science. 1998;282(5391):1145-7.

98. Coric D, Pettine K, Sumich A, Boltes MO. Prospective study of disc repair with allogeneic chondrocytes presented at the 2012 Joint Spine Section Meeting. J Neurosurg Spine. 2013;18(1):85-95.

99. Haufe SM, Mork AR. Intradiscal injection of hematopoietic stem cells in an attempt to rejuvenate the intervertebral discs. Stem Cells Dev. 2006;15(1):136-7.

100. Vadalà G, Sowa G, Hubert M, Gilbertson LG, Denaro V, Kang JD. Mesenchymal stem cells injection in degenerated intervertebral disc: cell leakage may induce osteophyte formation. J Tissue Eng Regen Med. 2012;6(5):348-55

101. Rathmell JP, Lake T, Ramundo MB. Infectious risks of chronic pain treatments: injection therapy, surgical implants, and intradiscal techniques. Reg Anesth Pain Med. 2006;31(4):346-52.

102. Nair MB, Baranwal G, Vijayan P, Keyan KS, Jayakumar R. Composite hydrogel of chitosan-poly(hydroxybutyrate-co-valerate) with chondroitin sulfate nanoparticles for nucleus pulposus tissue engineering. Colloids Surf B Biointerfaces. 2015;136:84-92.

103. Chen P, Ning L, Qiu P, Mo J, Mei S, Xia C, et al. Photo-crosslinked gelatinhyaluronic acid methacrylate hydrogel-committed nucleus pulposuslike differentiation of adipose stromal cells for intervertebral disc repair. J Tissue Eng Regen Med. 2019;13(4):682-93.

104. Naqvi SM, Gansau J, Gibbons D, Buckley CT. In vitro co-culture and ex vivo organ culture assessment of primed and cryopreserved stromal cell microcapsules for intervertebral disc regeneration. Eur Cell Mater. 2019:37:134-52.
105. Gan Y, Li S, Li P, Xu Y, Wang L, Zhao C, et al. A controlled release codelivery system of MSCs encapsulated in dextran/gelatin hydrogel with TGF- $\beta 3$-loaded nanoparticles for nucleus pulposus regeneration. Stem Cells Int. 2016;2016:9042019.

106. Zhang ZQ, Wang CS, Yang P, Wang KZ. Mesenchymal stem cells induced by microencapsulated chondrocytes on repairing of intervertebral disc degeneration. Orthop Surg. 2018;10(4):328-36.

107. Wu Y, Jia Z, Liu L, Zhao Y, Li H, Wang C, et al. Functional self-assembled peptide nanofibers for bone marrow mesenchymal stem cell encapsulation and regeneration in nucleus pulposus. Artif Organs. 2016;40(6):E112-119.

108. Kuang W, Liu C, Xu H. The application of decellularized nucleus pulposus matrix/chitosan with transforming growth factor $\beta 3$ for nucleus pulposus tissue engineering. Cytotechnology. 2021;73(3):447-56.

109. Choi UY, Joshi HP, Payne S, Kim KT, Kyung JW, Choi H, et al. An injectable hyaluronan-methylcellulose (HAMC) hydrogel combined with Wharton's Jelly-derived mesenchymal stromal cells (WJ-MSCs) promotes degenerative disc repair. Int J Mol Sci. 2020;21(19):7391.

110. Zhang H, Yu S, Zhao X, Mao Z, Gao C. Stromal cell-derived factor-1aencapsulated albumin/heparin nanoparticles for induced stem cell migration and intervertebral disc regeneration in vivo. Acta Biomater. 2018;72:217-27.

\section{Publisher's Note}

Springer Nature remains neutral with regard to jurisdictional claims in published maps and institutional affiliations.

Ready to submit your research? Choose BMC and benefit from:

- fast, convenient online submission

- thorough peer review by experienced researchers in your field

- rapid publication on acceptance

- support for research data, including large and complex data types

- gold Open Access which fosters wider collaboration and increased citations

- maximum visibility for your research: over $100 \mathrm{M}$ website views per year

At BMC, research is always in progress.

Learn more biomedcentral.com/submissions 